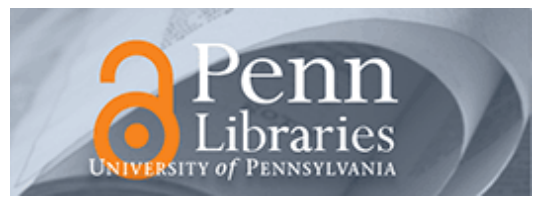

University of Pennsylvania ScholarlyCommons

1990

\title{
Der verschwundene Bote Metaphern und Modelle der Kommunikation
}

Klaus Krippendorff

University of Pennsylvania, kkrippendorff@asc.upenn.edu

Follow this and additional works at: https://repository.upenn.edu/asc_papers

Part of the Communication Commons

\section{Recommended Citation (OVERRIDE)}

Krippendorff, K. (1990). Der verschwundene bote metaphern und modelle der kommunikation. In K. Merten, S. J. Schmidt, \& S. Weischenberg (Eds.), Die wirklichkeit der medien; Eine einfÃ/4hrung in die kommunikationswissenschaft (pp. 79-113). Opladen: Westdeutscher Verlag. Retrieved from http://repository.upenn.edu/asc_papers/258

Postprint version.

This paper is posted at ScholarlyCommons. https://repository.upenn.edu/asc_papers/258

For more information, please contact repository@pobox.upenn.edu. 
Der verschwundene Bote Metaphern und Modelle der Kommunikation

Disciplines

Communication I Social and Behavioral Sciences

Comments

Postprint version. 
Manuscript developed for and translated into German by

Hessischer Rundfunk Funkkolleg "Kommunikation und Medien" (1990-91)

Studieneinheit 6

\title{
Der verschwundene Bote Metaphern und Modelle der Kommunikation
}

\author{
By \\ Klaus Krippendorff \\ The Annenberg School for Communication \\ University of Pennsylvania
}


Der verschwundene Bote

Metaphern und Modelle der Kommunikation

6.

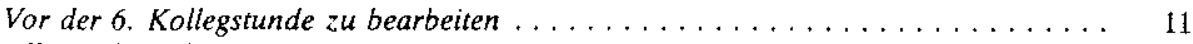

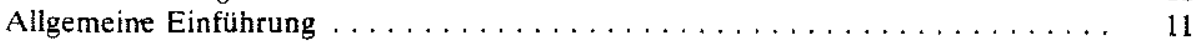

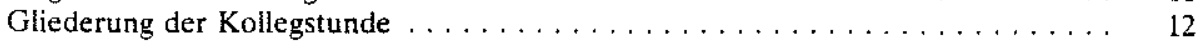

Wichtige in der Kollegstunde verwendete Fachausdrücke . . . . . . . . . . 13

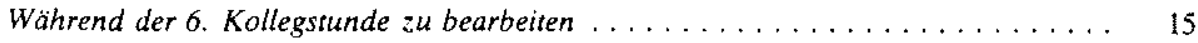

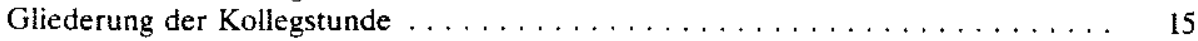

Arbeitsunterlagen .......................... 15

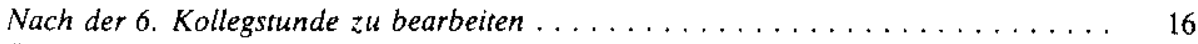

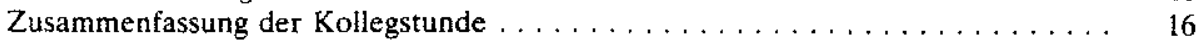

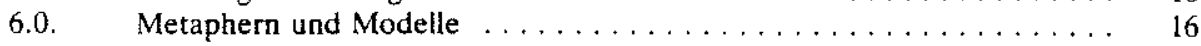

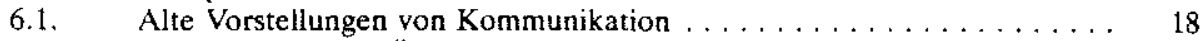

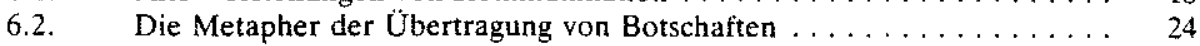

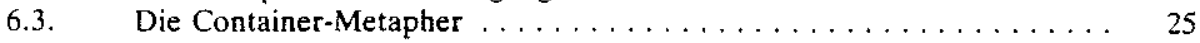

6.4. Die Metapher des Mitteilens von Gemeinsamkeiten (cognitive sharing) . 27

6.5. Die Metapher vom Argument als Krieg . . . . . . . . . . . . . . . . . 29

6.6. Die Metapher vom Kanal oder: Der Fluß der Signale . . . . . . . . . 30

6.7. Die mathematische Theorie der Kommunikation (Informationstheorie) . 32

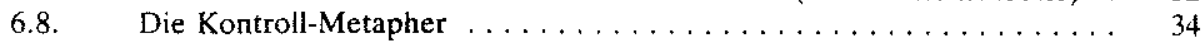

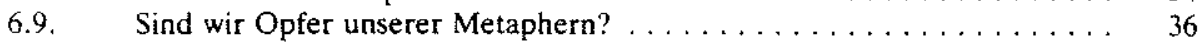

6.10. Eine konstruktivistische Auffassung von Kommunikation und ihrer

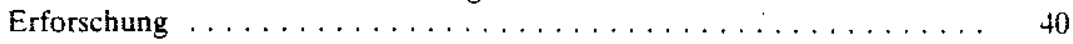




\title{
Der verschwundene Bote Metaphern und Modelle der Kommunikation
}

6.

\author{
Autor der Studieneinheit: Klaus Krippendorff \\ Klaus KriPpendorff (58), 1962 Diplom an der Hochschule für Gestaltung \\ in Ulm. $1967 \mathrm{Ph}$. D, an der University of Illinois/Urbana, 1970 honorary \\ M. A. von der University of Pennsylvania. Seit 1963 Professor of Commu- \\ nication an der Annenberg School for Communication an der University of \\ Pennsylvania in Philadelphia: Gastprofessuren in Berlin (1970), Delft/ \\ Niederlande (1973) und Columbus/USA (1986/87). 1984/85 Präsident der \\ International Communication Association (ICA). Veröffentlichungen zur \\ Informations- und Kommunikationstheorie, zur Kybernetik und System- \\ theorie und zur Methodik der Kommunikationsforschung, besonders der \\ Inhaltsanalyse. Mitheratsgeber mehrerer Fachzeitschriften.
}

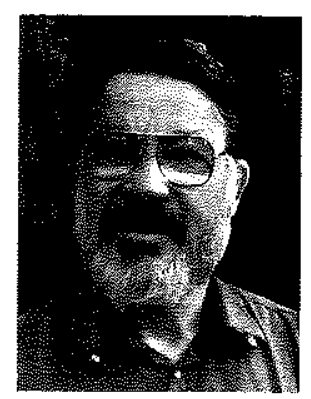

\section{Vor der 6. Kollegstunde zu bearbeiten}

\section{Aligemeine Einführung}

Kommunikation bezeichnet ein komplexes Netzwerk von Erscheinungen, dessen Grenze schwer zu ziehen und dessen Wesen schwer zu erfassen ist. Ihre wachsende Bedeutung aber beflügelt die Arbeit vieler: die des Ingenieurs, der ausgeklügelte Instrumente in ihren Diensten entwirft; die des Schriftstellers, der eine neue gedankliche Auseinandersetzung sucht; die des Therapeuten, der seine Klienten durch Konversation zu selbständigem Handeln befähigt, und die des Sozialwissenschaftlers, der versucht, all dies zu verstehen und sein Verständnis von Kommunikation der Öffentlichkeit mitzuteilen.

Die vielleicht weiteste Begriffsbestimmung von Kommunikation lautet: „Kommunikation ist die Koordination (im wesentlichen durch Sprache) des Zusammenlebens kognitiv autonomer Wesen innerhalb eines Mediums." Erst am Ende dieses Beitrags wird diese Definition Sinn machen. Daher sei zunächst mit gebräuchlicheren Begriffen begonnen und Kommunikation bestimmt als „ein Prozeß der Öbermittlung von Mustern von einem System zu einem anderen, wodurch unterschiedliche Räume, Zeiten und Formen überbrückt werden. "1 So kann etwa ein Buch zwischen seinem Autor und seinen Lesern über Tausende von Jahren hinweg vermitteln. Das Telefon kann Schallereignisse nahezu unmittelbar über Tausende von Meilen hinweg an einem anderen Ort wiedergeben. Briefe können ihrem Adressaten die verschiedensten Nachrichten vermitteln - von Liebesbotschaften, die zwischenmenschliche Beziehungen beeinflussen, wenn nicht gar etablieren, bis hin zu technischen Zeichnungen, die eine Kette unterschiedlichster Prozesse steuern. Somit werden Handlungsmuster und deren Variationen unterschiedlichen materiellen Formen und Medien schrittweise aufgeprägt. Auf die gleiche Weise, wie Priester den Gläubigen die Stimme Gottes vermitteln, übersetzen Dolmetscher Texte von einer Sprache in eine andere, machen Journalisten ihre Beobachtungen zu Nachrichten für ihre Leserschaft, halten Politiker Pressekonferenzen, veröffentlichen Wissenschaftler Theorien und Forschungsergebnisse.

Kommunikation muß nicht in Wiedergabe, Zustimmung oder Erfolg aufgehen. Sie kann zu Mißverstehen, Opposition, sich ergänzenden Auffassungen führen ebenso

1 Klaus Krippendorfa: Values, Modes and Domains of Inquiry into Communication. The Journal of Communication 2/1969, S. 107. 
wie zur Entstehung neuer Formen einladen. Kommunikation, so verstanden, ist nicht auf die soziale Welt beschränkt. Genetisches Material wird von einer Generation von Organismen auf die nächste Generation übertragen und transportiert damit die Botschaft der Art gewissermaßen in die Zukunft. Radio-Teleskope bringen viele Lichtjahre entfernte Bilder in unser gegenwärtiges Sichtfeld. Computer können veranlaßt werden, miteinander zu kommunizieren, um Probleme zu lösen, die deren Programmierer für wichtig halten.

Die scheinbare Universalität der Kommunikation, unsere Fähigkeit, so viele unterschiedliche Erscheinungen - vielleicht gar die gesamte Geschichte der Menschheit - aus dem Blickwinkel der Kommunikation zu betrachten, führt zu fundamentalen Fragen danach, wie wir Kommunikation denn verstehen können, wenn wir doch gar nicht über sie reden können, ohne sie schon vorauszusetzen, wenn sie so sehr Teil unseres eigenen Menschseins ist. Zur Beantwortung dieser Frage dienen uns einige Metaphern und Modelle, die in diesem Zusammenhang weithin als Hilfsmittel des Verstehens benutzt werden. Um zu verstehen, was hier modelliert wird und wie sich Muster kommunikativ bilden, eignen sich begriffliche Mittel, technische Modelle und sprachliche Metaphern am besten.

Lernziele Nach dem Durcharbeiten dieser Studieneinheit sollen Sie in der Lage sein,

- Begriffe von Kommunikation, die in früheren Kulturen verbreitet waren, zu erläutern;

- die Verbindung dieser alten Konzepte mit heutigen Modellen von Kommunikation aufzuzeigen;

- die wechselseitigen Einflüsse zwischen unseren alltäglichen Redeweisen und den wissenschaftlichen Theorien über Kommunikation zu beschreiben;

- die Bedeutung der Metaphern von Kommunikation als der Übertragung von Botschaften, der Mitteilung von Gemeinsamkeiten oder einem Fluß von Signalen einzuschätzen;

- den Einfluß, den Modelle von Kommunikationsprozessen und Massenkommunikationsprozessen auf unsere Lebenspraxis ausüben, zu erkennen.

\section{Gliederung der Kollegstunde}

\section{Rahmenhandlung}

Vorgeführt wird eine fiktive Redaktionsbesprechung in einer Hörfunkabteilung, bei der es um Klaus KrIPPENDORFFs Text und seine Vermittlung geht. Durch Interviews und Einspielungen werden fünf Thesen über die Massenmedien als Institutionen und die Arbeitsweise von Sozialwissenschaftlern illustriert. Die Produktion einer Kollegstunde des Funkkollegs steht stellvertretend für die Leistungen der Massenmedien.

\section{Massenmedien als Institutionen}

Massenmedien sind als Institutionen organisiert. Die in ihnen tätigen Personen handeln in verschiedenen Rollen: etwa als Hauptabteilungsleiter, als Redakteur oder als Sprecher. Zum „Medienspiel“ gehören weitere Akteure, wie Zuhörer, Werbeleute, politische Interessengruppen in den Aufsichtsgremien der Rundfunkanstalten und Techniker. Für Institutionen ist charakteristisch, daß sie eine Wirklichkeit erzeugen, in der sie sich entwickeln können und von der sie leben.

\section{Kosten der Kommunikation}

Viele „Medienmacher" denken sich Kommunikation als Kontrolle und die Hörer als kontrollierte Masse. Welche Vorstellungen sie und wir von der Massenkommunikation haben, prägt ihre und unsere Medienwirklichkeit. Für die Allgegenwärtigkeit der Medien zahlen wir einen Preis. Die Selbständigkeit unserer 
Denkleistung wird eingeschränkt - es sei denn, jeder Hörer benutzt seinen eigenen Kopf und entnimmt dem Radio Beiträge zu eigenem Handeln anstelle von oben autorisierter und damit zwingender Tatsachen.

\section{Kommunikationsforschung und Massenmedien}

Wir befinden uns in einem Kreislauf: Wie wir über Kommunikation und Medien denken und sprechen, beeinflußt unser Medienverhalten und findet sich dann in den wissenschaftlichen Modellen von Kommunikation und Medien wieder. Und die wissenschaftlichen Veröffentlichungen wirken auf die Alltagssprache zurück. Auch zwischen den Modellen der Medienforschung und der herrschenden Medienpraxis besteht ein wechselseitiger Einfluß. Indem die Wissenschaft die existierenden Kommunikationspraktiken als gegebene Tatsachen untersucht und die Ergebnisse durch Publikationen den daran interessierten Personen zuspielt, unterstützt sie - oft unbewußt - die herrschenden Institutionen.

\section{Medien und Wirklichkeit}

Massenmedien sorgen für eine Welt, in der ihre Existenz als unentbehrlich und ihre Leistung als unersetzlich erscheinen. Sie liefern Themen für das persönliche Gespräch, stellen Angebote für gemeinsame Wirklichkeit bereit und verbinden Menschen-sie wirken integrativ. Und sie gefährden durch diese Leistungen unsere individuelle Urteilsfähigkeit, unsere kognitive Autonomie.

\section{Kommunikation und Zusammenleben}

Nicht nur die Tätigkeit der Massenmedien, sondern alle zwischenmenschlichen Kommunikationsformen beruhen auf sozialen Konstruktionen. Als solche bedürfen sie der individuellen Fähigkeit der jeweiligen Kommunikationspartner, sich gegenseitig so zu konstruieren, daß sie zueinander passen und daß die daraus folgenden wechselseitigen Handlungen die kognitive Autonomie der Teilnehmer nicht außer Kraft setzen.

\section{Wichtige in der Kollegstunde verwendete Fachausdrücke}

Institution: gesellschaftliche Konstruktion einer sozialen Einrichtung, die, in individuellen Vorstellungen verankert, spezifische Handlungen, Verhaltensregeln und Organisationsformen sozialer Gruppen reguliert. Diese Einrichtungen werden durch die Übereinstimmung der Mitglieder einer Gesellschaft oder durch Macht etabliert. Erst wenn typisierte Handlungen und Rollen von den Mitgliedern einer Gesellschaft gegenseitig erwartet werden, so daß jeder sein eigenes Handeln ausrichten und das Handeln anderer mit diesen Erwartungen verstehen kann, sind sie wechselseitig festgelegt, also institutionalisiert. Beispiele für Institutionen in unserer Gesellschaft sind die Familie, die Kirche, die Verwaltung oder die Massenmedien.

Kognitive Autonomie: Dem Konzept des Radikalen Konstruktivismus zufolge werden Erkennen und Verstehen nicht durch die äußere Welt verursacht oder kontrolliert, sondern jeder Mensch konstruiert - in der Kommunikation mit anderen Personen - seine eigene Welt. Diese Selbständigkeit der individuellen Denk- und Erkenntnisleistungen wird als „kognitive Autonomie“ bezeichnet. Sie wird grundsätzlich gefährdet oder eingeschränkt durch die Fähigkeit der Medien, eine nach ihren Gesetzen geformte Welt zu konstruieren und zu verbreiten.

Kommunikation: umgangssprachlich „Austausch“, „Wissensvermittlung“, „Senden und fehlerfreies Empfangen von Botschaften“, aber auch „Steuerung von Wirkungen". Die Erkenntnistheorie des Radikalen Konstruktivismus postuliert hingegen, daß Kommunikation, einschließlich umgangssprachlich 
vermittelter Vorstellungen, eine soziale Konstruktion ist, in der die von ihr abgeleiteten Wechselwirkungen die kognitive Autonomie der Kommunikationsteilnehmer bewahren. Man unterscheidet einseitige (wie beim Rundfunk) und wechselseitige (wie beim Gespräch) Kommunikation. Häufig werden technische Realisationen als Kommunikationsmodelle benutzt. Innerhalb zwischenmenschlicher Kommunikationsprozesse spielen vier Aspekte entscheidende Rollen: die gegenseitige Konstruktion der Kommunikationsteilnehmer; das wechselseitige Bestimmen eines Kommunikationskontextes (Situation) einschließlich eines variablen Mediums und stabiler Beziehungen zwischen den Teilnehmern; eine die Veränderung des eigenen Wissensstandes reflektierende Konstruktion von Information, solange diese mit dem Verhalten des Mediums als vereinbar angesehen werden kann; und die daraus erwachsenden Kommunikationshandlungen, die in der Erwartung konzipiert sind, von den jeweils anderen Kommunikationspartnern verstanden zu werden.

Konstruktion: Als Attribut des Wissens ist der Begriff auf das Herstellen von Wirklichkeiten, auf das Aufbauen, Austeilen und Sich-bilden von Erkenntnissen gerichtet. In der kybernetischen Erkenntnistheorie sind Konstruktionen weder in jemandes Kopf noch in einer beobachterunabhängigen Realität zu finden. Sie sind in einem kreisförmigen Prozeß von Wahrnehmung, Denken und Handeln zu Hause. Soziale Konstruktionen nehmen daruber hinaus den Sprachgebrauch anderer in sich auf und operieren komplementär zueinander, wie die Konstruktionen von Selbst und anderen Personen, von Richter und Gerichtetem, Ehemann und Ehefrau oder Redner und Zuhörer. Die Konstruktion des einen kann dann ohne die Konstruktion des anderen nicht existieren.

Kontroll-Metapher: Vorstellung von Kommunikation als Kontrolle, als Quelle und Instrument der Macht. Sie geht bis in die antike Rhetorik zurück. Die Beherrschung der Sprache und die Kunst der freien Rede dienen danach der Beherrschung anderer Menschen. Zahlreiche Studien über die Wirkungen der Massenmedien enthalten - ausgesprochen oder unausgesprochen - diese Vorstellung. Sie unterstellen, daß die Informations- und Unterhaltungsangebote unter bestimmten Bedingungen das Denken und Handeln der Leser, Hörer und Zuschauer kontrollieren.

Massenmedien: Sie produzieren und verbreiten Aussagen für ein großes, unterschiedlich zusammengesetztes Publikum. Es handelt sich dabei um Organisationen, die im Prinzip genauso arbeiten wie andere Industriebetriebe in der modernen Gesellschaft. Grundlage für das Entstehen von Massenmedien - beispielsweise Tageszeitung oder Hörfunk - waren technische Entwicklungen am Ende des 19. und am Beginn des 20. Jahrhunderts.

Metapher: Prozeß, ein gewöhnlich wenigen bekanntes oder komplexes Phänomen, mit den Begriffen eines damit eigentlich nichts zu tun habenden Phänomens in Erfahrung zu bringen. Beispielsweise wird mit den aus der Welt des Computers stammenden Begriffen wie "Information“, „Codierung" oder "Speicherung“ versucht, das Verhalten des menschlichen Gehirns zu verstehen. Metaphern tragen gewöhnlich unreflektierte Implikationen in das durch sie Verstandene. So führt die Computer-Metapher dazu, das Gehirn als determiniertes System zu sehen und Informationseingaben für sein Verhalten verantwortlich zu machen. Sagt man, daß dieser Satz etwas „beinhaltet“ (wie ein Gefäß), obwohl er nur aus Buchstaben zusammengesetzt ist, ist er nur metaphorisch zu sehen. Die Container-Metapher impliziert, daß Inhalte für Sender und Empfänger gleich sind. Metaphern sind keinesfalls als falsch abzuweisen. Sie bestimmen unsere Wahrnehmung. 


\section{Während der 6. Kollegstunde zu bearbeiten}

\section{Gliederung der Kollegstunde}

1. Prolog

2. Massenmedien als Institutionen

3. Kosten der Kommunikation

4. Kommunikationsforschung und Massenmedien

5. Medien und Wirklichkeit

6. Kommunikation und Zusammenleben

\section{Arbeitsunterlagen}

Die Kollegstunde behandelt fünf Thesen von Klaus Krippendorff

1. Als Institutionen konstituieren sich Massenmedien genau in den sozialen Wirklichkeiten, die sie selbst zu erzeugen in der Lage sind und von denen sie danach leben.

2. Massenmedien etablieren sich auf Kosten der kognitiven Autonomie aller ihrer Teilnehmer.

3. Massenmedien operieren in einer Ökologie von Modellen, Metaphern und Mythen der Kommunikation; sie unterstützen und verbreiten aber nur solche, die ihre Lebensfähigkeit als institution nicht gefährden.

4. Erkenntnistheoretische Ignoranz oder institutionelle Blindheit zeigt sich, wenn sich Sozialwissenschaftler bei ihrer Beschäftigung mit menschlicher Kommunikation an eine bestimmte Definition von Kommunikation klammern und dann die entsprechenden Formen menschlichen Zusammenlebens so beschreiben.

5. Prozesse zwischenmenschlicher Kommunikation, einschließlich der institutionalisierten Massenkommunikation, sind soziale Konstruktionen und können nicht ohne das kognitive Involviertsein ihrer Teilnehmer verstanden werden. 


\section{Nach der 6. Kollegstunde zu bearbeiten}

\section{Zusammenfassung der Kollegstunde}

Massenmedien sind Institutionen. Als Beispiel einer solchen Institution und ihrer Arbeitsweise dient eine Rundfunkanstalt, genauer: die Produktion der 6 . Kollegstunde für das Funkkolleg ,Medien und Kommunikation“ über fünf Thesen von Klaus KRipPENdorFF. An der Institution und ihren Leistungen sind zahlreiche Menschen in verschiedenen Funktionen beteiligt: als Intendant oder Redakteur, als Techniker oder Gremienmitglied, als Auftraggeber für Werbung oder als Zuhörer. Eine solche „Arbeitsteilung“ weisen alle gesellschaftlichen Einrichtungen auf. Das besondere Merkmal der Massenmedien besteht darin, daß sie nicht nur auf geselischaftliche Kommunikations formen zurückgreifen, sondern mit diesen Kommunikationsformen zusammenfallen. Was bei allen anderen Institutionen lediglich ein Mittel zum Zweck ist - nämlich ihre Umwelt auszunutzen -, ist Kommunikation für die Massenmedien das begründende und erhaltende Element. Die Kommunikation unter den Teilnehmern des „Medienspiels“ ist es, was diese Institution von allen anderen unterscheidet.

Auch wir sind als Leserinnen und Leser, Hörerinnen und Hörer, Zuschauerinnen und Zuschauer in diesen Kreislauf einbezogen. Welche Vorstellungen wir von unserer Rolle im „Medienspiel" besitzen, prägt ganz entscheidend unsere Medienwirklichkeit. Wir können uns - vereinfacht formuliert - als von den Medien abhängig oder als selbständige Individuen mit je eigenem Urteilsvermögen fühlen und diesen Vorstellungen gemäß handeln.

In einen ähnlichen Kreislauf ist auch die Kommunikationswissenschaft eingebunden. Thre Konzepte von (Massen-)Kommunikation erzeugen Konstruktionen von Wirklichkeit. Lange Zeit dachten sich viele Forscher die Massenkommunikation als einen Prozeß, der aus Ursachen (Botschaften) und Wirkungen (Publikumsreaktionen) besteht. Dieses vom Kausaldenken geprägte Bild fand auch in der Hörerforschung viel Anklang. Zudem paßte es allzu gut in die Vorstellungen der Medienpraktiker - egal, ob sie mit ihrer Kritik Gehör finden, mit ihrer Werbung Produkte verkaufen oder mit ihren Wahispots Wählerstimmen für sich gewinnen wollen.

Wie andere Institutionen erzeugen Massenmedien eine Wirklichkeit, von der sie leben und in der sie sich entwickeln können. Diese Wirklichkeit läßt die Existenz der „Institution Massenmedien" als unentbehrlich und ihre Leistungen als unersetzbar erscheinen. Im Zeitalter der Universalität, der Allgegenwärtigkeit von Massenmedien wird uns glaubbar gemacht, daß wir auf ihre Informations-, Unterhaltungs- und Wirklichkeitsangebote nicht verzichten können. Wer dies dennoch tut, wird leicht zu einem Außenseiter gestempelt. Darin zeigt sich die konstruierte Verwurzelung unserer Realität in den Massenmedien.

Die Begriffe und Modelle der Wissenschaftler gedeihen auf dem Boden unserer Umgangssprache. Die beim Sprechen nur selten bedachten Metaphern der Kommunikation prägen unsere Redeweisen - und somit unsere soziale Wirklichkeit.

Nicht nur die Massenmedien, sondern auch alle Formen zwischenmenschlicher Kommunikation sind soziale Konstruktionen. Ihre Grenzen liegen in der wechselseitigen Vorstellung voneinander, über die zwei Kommunikationspartner verfügen. Als Beispiel für diese These diente die Funkkolleg-Redaktion mit ihren Arbeitsabläufen und Kommunikationsregein.

\subsection{Metaphern und Modelle}

An einem komplexen Wirtschaftssystem und einem Modell dieses Systems wird erkennbar, was Modelle für uns leisten können. Unsere Fähigkeit, mit dem Wirtschaftssystem experimentieren und von den Folgen dieser Experimente lernen zu können, ist stets auf das beschränkt, was seine Teilnehmer - Produzenten, Verbraucher, Geschäftsleute, Bankiers, Produzenten, Ökonomen, Politiker - zu dulden bereit wären. Mit einem Computer-Modell solch eines Systems wäre man nicht nur in der Lage, sehr viel mehr Daten zu erfassen, als es ein Mensch jemals könnte, sondern auch, sehr viel freier mit dem System spielen zu können, ohne dabei das gesamte Wirtschaftssystem zu stören oder gar dessen Teilnehmer zu gefährden. Mit Hilfe eines Computer-Modells kann man offensichtlich die 
kühnsten wirtschaftspolitischen Strategien durchspielen; man kann Faktoren einfügen, um Krisenpunkte aufzuspüren oder Revolutionen zu berechnen; man kann Veränderungen viele Jahre vor ihrem Eintreffen studieren; man kann die Lebensfähigkeit möglicher Wirklichkeiten testen, und vieles andere mehr. Modelle können uns helfen zu verstehen, was das Modellierte uns verschweigt.

Modelle sind nicht an Computer gebunden. So kann etwa eine Modellstadt ein hervorragendes Beispiel dafür sein, wie andere Städte funktionieren sollten. Die Beschäftigung mit einer solchen Modellstadt könnte uns dann etwa vor Augen führen, mit welchen Problemen in den ihr nachgebildeten Städten zu rechnen ist. Viele zweckorientierte, funktionale Objekte können zum Modell erklärt werden und dann als Norm dienen. Man denke etwa an vorbildliche Bürger, ModellGemeinschaften, exemplarische Reden, beispielhafte Sendeanstalten und natürlich auch an Modelle der Kommunikation. Die Erforschung eines Objekts in den Begriffen eines anderen, das Frei-Machen des eigenen Denkens von den Zwängen herrschender Praktiken, etwas durchzusprechen, bevor man handelt - all dies sind grundlegende Eigenschaften menschlicher Kommunikation.

Frühe Kommunikationsmodelle waren weitgehend der Technologie entlehnt, wofür heutige Computermodelle noch immer ein Beispiel sind. Modelle können aber oft auch sprachlicher Natur sein oder Aussagensysteme darstellen, die eine schlüssige Beschreibung des Was, Wie oder Warum von Kommunikation liefern. Sie stellen dabei metaphorische Beziehungen zu solchen mechanischen Gebilden, physikalischen Prozessen oder gesellschaftlichen Rollen her, die wir bereits gut kennen. Wenn jemand sagt, Kommunikation sei das Nervensystem der Gesellschaft, so benutzt er den Begriff „Nervensystem" als biologische Metapher, um ein begriffliches Modell von gesellschaftlicher Kommunikation zu konstruieren. Jede Metapher hat die Eigenschaft, eine erklärungskräftige Struktur aus einem bekannten Erfahrungsbereich in einem anderen anzuwenden, der entweder noch erklärungsbedürftig ist oder den es neu zu verstehen gilt. Auf diese Weise gibt die Metapher einem unvertrauten oder unzureichend strukturierten Erfahrungsbereich eine neue Klarheit, Offensichtlichkeit und greifbare Gestalt. Metaphern bieten sogar eine sehr viel größere Experimentierfreiheit als physikalische Modelle. Zugleich aber werden die unkritischen Benutzer von Metaphern leicht dazu verführt, die damit geschaffene Neufassung von Wirklichkeiten als Tatsächlichkeiten zu sehen und ihre Implikationen als selbstverständlich anzunehmen.

Die Metapher „Familienoberhaupt“ ist ein gutes Beispiel dafür. Sie überträgt Erfahrungen mit lebenden Organismen auf den Familienbereich. Die volkstümliche Biologie macht uns glauben, der Kopf sei ein ganz besonderes Glied des Körpers. Er ist der Sitz des Gehirns und der Ort, an dem Entscheidungen gefällt werden. Entfernt man den Kopf eines Lebewesens, so kann der übrig bleibende Teil des Körpers nicht mehr leben. Auf eine Familie angewendet, weist diese Metapher einem Mitglied die wichtigste Rolle zu, macht es zum einzigen, das wirklich zählt, zum Verantwortlichen, von dem alle anderen abhängen. Die Implikate des unwidersprochenen Gebrauchs dieser Metapher liegen im Verhalten der Familienmitglieder untereinander. Klopft ein Interviewer an die Tür und bittet, das Familienoberhaupt sprechen zu dürfen, so weiß jeder, wer gemeint ist. Diese Metapher läßt kaum annehmen, daß auch die Hände und Füße der Familie über interviewwürdige geistige Fähigkeiten verfügen könnten. Eine sprachbewußte Ferministin wird Einwände gegen den Gebrauch dieser Metapher erheben und sich weigern, ihren Implikaten zu folgen. Damit wären die mit dieser Metapher verquickten individuellen Wirklichkeitskonstruktionen, ganz gleich welcher Art, herausgefordert und ein Prozeß in Gang gebracht, an dessen Ende eine andere Metapher für die Familie und vielleicht gar eine neue soziale Wirklichkeit stehen könnten. 
Da jedes Reden über Kommunikation immer schon das Verstricktsein des Sprechers in seine eigenen Konstruktionen von Kommunikation aufzeigt, liefern die Metaphern, Modelle, Mythen und andere umgangssprachliche Konstruktionen von Kommunikation einen günstigen, wenn nicht gar den einzigen Einstiegspunkt in unser Thema: die sozialen Implikationen von Metaphern und Modellen im Medium ihrer Beschreibung - also der von uns benutzten Sprache - zu verdeutlichen.

Deshalb bleiben wissenschaftliche Kommunikationsmodelle zunächst im Hintergrund. Der Schwerpunkt, zumindest am Anfang dieses Beitrags, wird auf einer alltagssprachlichen Erklärung von Kommunikation liegen, auf Metaphern, die wir im Alltag häufig - wenngleich oft unbewußt - verwenden, auf volkstümlichen Modellen, in deren Kategorien wir zu denken und zu handeln gewohnt sind. Obwohl ich mich also anfangs auf die Weisheit der Alltagssprache verlasse, um die sprachliche Grundlage des Verstehens von Kommunikation deutlich machen zu können, behaupte ich überdies, daß Sozialwissenschaftler es kaum vermeiden können, ihre Theorien in solchen Alltagsvorstellungen wurzeln zu lassen.

Aufgabe 1 Was leisten Metaphern und Modelle für das Verständnis von Systemen, beispielsweise von Kommunikationssystemen?

\subsection{Alte Vorstellungen von Kommunikation}

Ansatz 1 Kommunikation geschah nicht immer so, wie wir sie oben definierten. Gehen wir einmal ungefähr fünftausend Jahre zurück, ins damalige Babylon oder Ägypten, wo, wie wir glauben, die Schrift entstanden ist. Dort finden wir keinen Hinweis dafür, daß Kommunikation als solche aufgefaßt wurde. Und dies ist keineswegs überraschend. Jedes uns universell umgebende Medium des Lebens ist schwierig wahrzunehmen. Die Schwerkraft zum Beispiel wurde erst in der Neuzeit „entdeckt“, weil sie in praktischen Situationen überall gegenwärtig ist. Und da Kommunikation, vielleicht sollte man hier besser von "Sprache" oder von "Sprechen" reden, eine den Menschen bestimmende Fähigkeit ist, schien es für eine lange Zeit nur natürlich, sie als selbstverständlich vorauszusetzen. Dennoch brachte die Einführung der Schrift so manche Störung der ,natürlichen“ Lebenspraxis mit sich und führte zu anfänglichen Vorstellungen von dem, was wir heute als Kommunikation auffassen.

- Neben ihrer Funktion als Hilfe beim Zählen und bei der Buchführung erscheint die frühe Schrift Ägyptens hauptsächlich auf wichtigen öffentlichen Gebäuden und auf den Wänden der Grabkammern der Pharaonen, die allesamt für die Ewigkeit entworfen waren. Die Schriften nennen Erbfolgen der Herrscher, bedeutende Errungenschaften, erinnerungswürdige öffentliche Ereignisse, religiöse Anwei- 
sungen und nicht zuletzt auch Gründe, warum die jeweiligen Gebäude errichtet wurden. In Stein gemeißelte Bildinschriften konnten weder einfach verändert werden (obwohl unfreundlich gesonnene Nachfolger das mitunter taten) noch an einen anderen Ort gebracht werden (wenn auch die Römer ägyptische Obelisken als Souvenirs mitnahmen); sie teilten ihren Lesern nichts anderes mit als das, was sie schon wußten, aber nicht vergessen sollten: das staatsbürgerliche Wissen, das ihnen im Gedächtnis bleiben sollte, und welches Gesetz für diejenigen galt, die mit diesen Gedächtnisstützen lebten.

Diese monumentalen Inschriften konnten kaum als einseitige Kommunikation gesehen werden etwa von einem Pharao an sein Volk. Sie waren ständig gegenwärtig; sie zeigten nachdrücklich die Macht rechtsgültiger Autorität; sie führten sichtbar die herrschende soziale, politische und religiöse Wirklichkeit vor Augen. Diese archaische Vorstellung von Kommunikation möchte ich als „Kommunikation ist die Schaffung von Monumenten" zusammenfassen. Monumente sind dabei nicht auf steinerne oder metallene Strukturen und Objekte beschränkt. Monumente sind Manifestationen einer Geschichte und einer Zukunft, in der es keine Änderungen gibt. Monumente garantieren die Dauerhaftigkeit sozialer Beziehungen, die durch keine jahreszeitlichen Veränderungen, Kriege, Auswanderungen, nachfolgende Herrscher oder neue Generationen von Einwohnern gestört werden darf. Wer ihre Leser sind - und womöglich auch ihre Autoren -, ist völlig nebensächlich. Die bloße Gegenwart monumentaler Inschriften reicht vermutlich aus, um jedermanns Fügsamkeit sicherzustellen.

Die Idee, eine solche fundamentale menschliche Aktivität wie Kommunikation mit der Erschaffung von Monumenten gleichzusetzen, könnte schon zu finden sein in den etwa fünfzehntausend Jahre alten paläolithischen Höhlenzeichnungen von Lascaux. Diese frühesten uns bekannten künstlerischen Dokumente zeigen Tiere, manchmal verschmolzen mit menschlichen Gestalten. Wir wissen zwar nicht viel von den Personen, die ihre Magie in diese Zeichnungen eingebracht haben, wir nehmen aber heute an, daß diese Zeichnungen das Verständnis der Beziehungen
Abb. 1: Der Stein von Rosetta. 196 v. Chr. Gefunden 1799 in Rashid im Nildelta. London, Britisches Museum

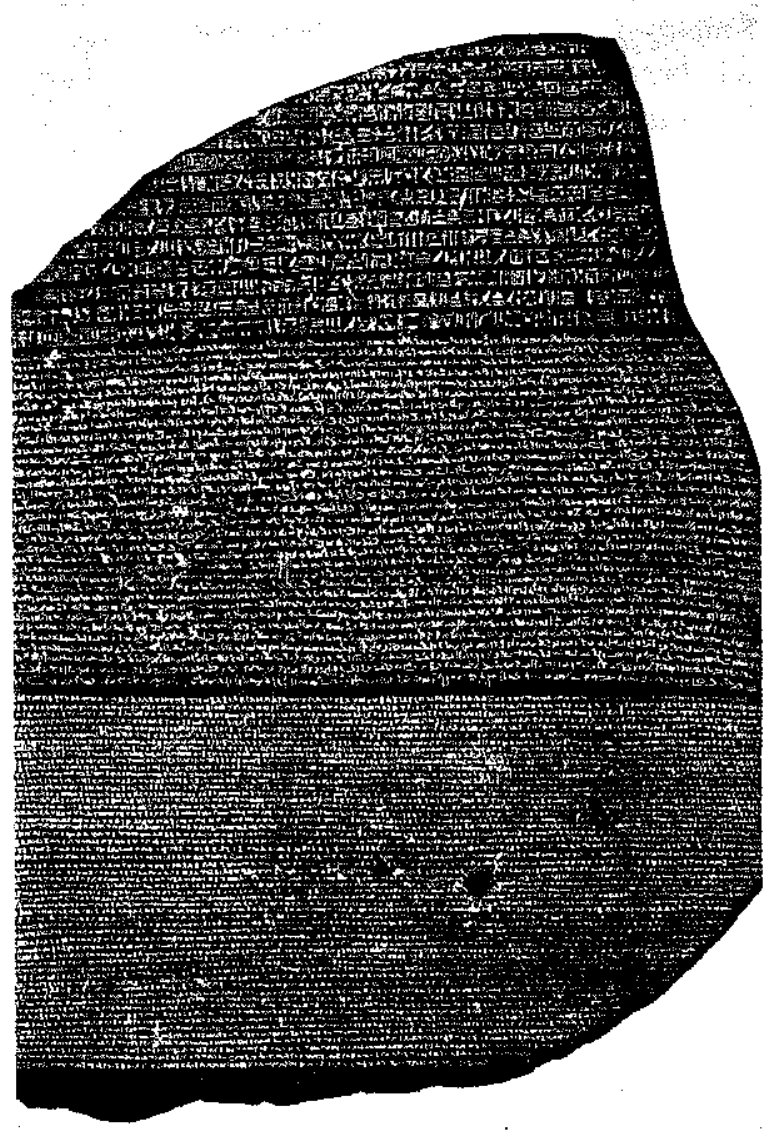

Die gleichlautenden Inschriften sind in hieroglyphischer, demotischer und griechischer Sprache abgefaßt.

Aus: Gustav BakfHFi: Konnte Adam schreiben? Weltgeschichte der Schrift. Beurbeitet und herausgegehen von Karl Gurbrod. Köln 1972, Abb. 10. 
zwischen den Höhlenbewohnern und ihrer natürlichen Umgebung regelten. Sie identifizierten die Maler als Jäger und versprachen ihnen möglicherweise dauerhaften Erfolg bei der Nahrungssuche und vielleicht auch Schutz vor unberechenbaren wilden Tieren. Magie verschmilzt den Unterschied zwischen Wirklichkeit und Bildern; und so gibt es kaum Grund zu der Annahme, diese Zeichnungen seien bloße Abbildungen gewesen in einer Art, wie wir heute Fotos interpretieren. Sehr wahrscheinlich waren sie ein nicht entfremdeter Bestandteil einer Stammesidentität und stellten dar, was wissenswert oder zu verehren war. Sie waren Monumente im Leben der Stammesmitglieder.

Die Gleichsetzung von Kommunikation mit der Schaffung vion Monumenten besteht heute noch. Beispiele dafür sind vertraute Bildnisse kulturell bedeutsamer Persönlichkeiten, Mahnmale für die in Kriegen Gefallenen, die Milliarden von Grabsteinen überall auf der Welt, aber auch LuTHERS Thesen, HochzeitsanzeigenoderWerbungfürneue Produkte in Zeitungen, auch die Insignien, die Touristen auf historischen Sehenswürdigkeiten anläBlich ihres Besuchs hinterlassen - allesamt haben sie im Grunde denselben Status: Eine selbsternannte Autorität schafft ein dauerhaftes Beweisstück für jemanden oder für etwas, das ihm wichtig scheint, oft an einem öffentlich, rechtlich oder persönlich bedeutsamen Übergangspunkt wie einer Thronbesteigung, einem Todesfall, dem Ende eines Krieges oder einem neuen Lebensabschnitt. Man denke einmal daran, wie oft und bei welchen fast rituellen Anlässen heutige Politiker gebeten werden, „eine Erklärung abzugeben“, „Stellung zu nehmen“, „ein Problem zu definieren“, oder daran, was Menschen tun, um „ihren Status zu signalisieren": durch Leistung, Kleidung oder Besitztümer; wie wichtig es ist, "wieder für geordnete Verhältnisse zu sorgen", wenn das persönliche Ansehen befleckt wurde oder man vom rechten Wege abgekommen war. Die Congressional Records, offizielle Veröffentlichungen des amerikanischen Kongresses, stellen zum Beispiel nicht dar, was im Abgeordnetenhaus tatsächlich geschah. Da jedes Kongreßmitglied seine Reden redigieren und Material einfügen kann, das so nie verlesen wurde, sind diese Veröffentlichungen selbstgefällige öffentliche "Monumente" der Abgeordneten. Monumente erfordern weder Übertragung von Information noch Rückmeldung von Lesern. Es scheint hinreichend, Monumente durch den Akt des Hinstellens für solche zu erklären.

- Eine weitere alte Vorstellung von Kommunikation findet sich in der Wurzel unseres modernen Wortes „Symbol“. Es geht zurück auf das griechische „symbolon", eine Münze, die von zwei Freunden entzweigebrochen wurde und deren Hälften jeder getrennt mit sich trug in der Hoffnung, daß dies sie einst wieder zusammenführen werde. Diese Hälften bedeuteten je für sich gar nichts. Ihre magische Kraft entfaltete sich durch die Einheit, von der nur ihre Träger wußten. Der Begriff von "Kommunikation als Symbolon" enthält die Idee von Gemeinsamkeit, von gemeinsamer Geschichte, von gemeinsam geteiltem Wissen. Diese Idee findet man mehr oder weniger auch in der modernen Auffassung von 
Kommunikation. Übrigens entsprach die Funktionsweise des Symbolons recht genau den damals angenommenen physikalischen Gesetzmäßigkeiten. ARISTOTELES zufolge hatte jedes Ding stets seinen (natürlichen) Bestimmungsort zu finden: Rauch mußte emporsteigen, Steine mußten fallen, so daß es nicht überrascht, daß ein Symbolon sich wiedervereinigen mußte. Die Teile eines Symbolons paßten zueinander, die Bruchstücke ergänzten sich wie Spiegelbilder, und die Wiederherstellung der einstigen Einheit war ihr endgültiger Zweck. Die Statuen, welche die Griechen uns hinterlassen haben, könnten durchaus als Teile einer Einheit geschaffen worden sein, einer Einheit, die jedermann durch Betrachten vervollständigen konnte, und nicht als Abbilder, als Repräsentation, als die wir sie heute sehen wollen. Deshalb darf man „Kommunikation als Symbolon" nicht verwechseln mit der Abbildungsfunktion, die wir mit dem modernen Begriff des Symbols verbinden.

- Die dritte in der Antike verankerte Vorstellung verweist auf ein Konzept von „Kommunikation als das, was göttlich inspirierte Boten tun“. Im Jahre $490 \mathrm{v}$. Chr., nach der großen Schlacht bei Marathon gegen die Perser, rannte ein Läufer (von dem man sagt, er sei am Ziel tot zusammengebrochen) 42,195 Kilometer, um die Siegesnachricht nach Athen zu bringen. Das Bemerkenswerte an dieser Geschichte ist, daß die Griechen von der physischen Leistung des Läufers äußerst angetan waren. Noch heute feiern wir sie als athletischen Erfolg, während die gleichzeitige Botschaft unbeachtet blieb - was uns Anlaß zu Spekulationen gibt. Natürlich kannten die Griechen Hermes, den Gott, der als Bote anderen Göttern diente. Die Idee des Boten gab es also ganz ohne Zweifel. Der Läufer von Marathon war nun weder ein Gott noch durch irgendein übernatürliches Wesen inspiriert. Er hatte „nur gesehen“, was er sagte. Es könnte durchaus so gewesen sein, daß das Konzept des Boten ohne göttlichen Auftrag unanwendbar blieb. Inspiriert zu werden, dürfte zur damaligen Zeit üblich gewesen sein. Folgt man Julian JAYNEs, so war es den Griechen bis zur Zeit der "Ilias" im wesentlichen unbekannt, individuelle Verantwortung für ihr Handeln zu übernehmen. ${ }^{1}$ Sie hörten Stimmen in ihren Köpfen, die sie Göttern zuschrieben, und handelten so, als führten sie deren Aufträge aus. Um ein Bote zu sein, mußte man zu den entsprechenden Handlungen von ,höheren Instanzen“ inspiriert worden sein. Wir wissen nicht recht, wie Moses aus der Sicht der Israeliten die Gebote Gottes vom Berge Sinai brachte. MонаммеD aber verstand sich ohne Zweifel als Bote und Prophet Allahs - als ein Medium, durch das ein Gott zu seinem Volk sprach.

Indem die göttlich inspirierten Boten Genauigkeit der mündlichen Wiedergabe für sich in Anspruch nahmen, wiesen sie zugleich die Verantwortung für die wiedergegebenen Inhalte von sich. Die alte Bedeutung von "Botschaft" ist "Auftrag", und in der auf mündlicher Überlieferung beruhenden Kultur waren Boten entsprechend Beauftragte auf göttliches Geheiß. Aus den Pflichten des Hermes kann man übrigens in etwa ersehen, was es hieß, ein Bote zu sein. Er herrschte über Straßen, Handel, Erfindung, Beredsamkeit, List und Diebstahl. Zweifellos hängen diese Gebiete im Wesen mit heutigen Kommunikationsbegriffen zusammen. Doch darf man nicht außer acht lassen, daß Hermes, um ein Bote zu sein, für andere Götter sprechen mußte.

- Die vierte alte Vorstellung könnte man umschreiben als „Kommunikation ist, mit Argumenten umgehen". Die fehlende Einheit unter den griechischen Stadtstaaten und der nachfolgende Untergang der Aristokratie brachten viele öffentliche Angelegenheiten in die Debatte, deren Wahrheit ungewiß war und die es zu klären galt. An modernen Maßstäben gemessen ist eine Debatte ein Kommunikationsprozeß. Die Wissenschaft der Rhetorik, die im zunehmenden Bewußtsein für die

1 Julian JAynes: The Origin of Consciousness in the Breakdown of the Bicameral Mind. Boston 1976, S. 286. 
Abb. 3: Marc Chagall: Moses empfängt die steinerne Gesetzestafel aus der Hand des unsichtbaren Gottes. Nizza, Museum "Biblische Botschaft"

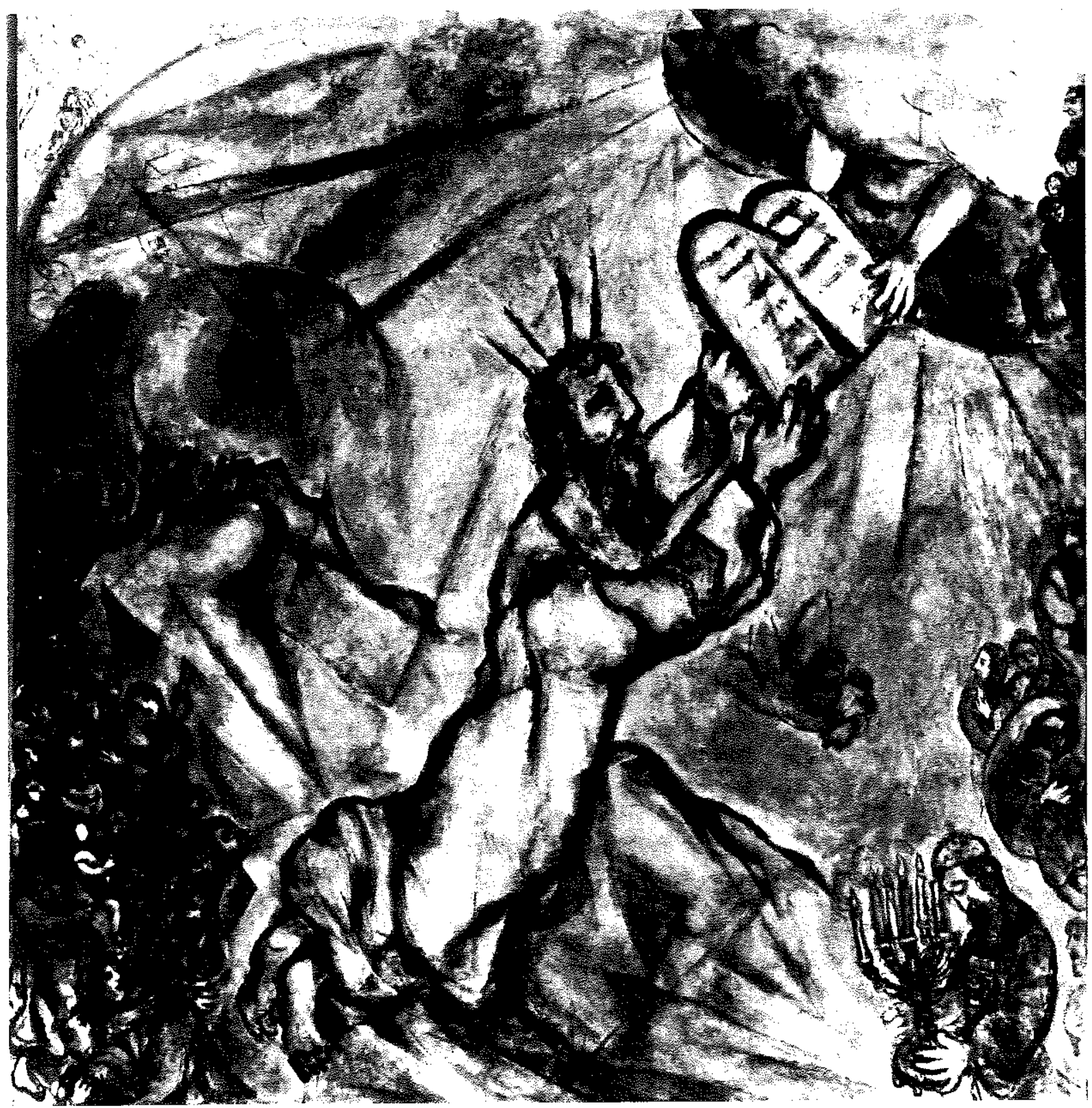

Rolle der Sprache bei den zu klärenden Problemen dieser Zeit entstand, beschäftigte sich jedoch im wesentlichen mit Fragen der richtigen Argumentation, mit logisch folgerichtigem Denken, mit bildhaften Ausdrücken oder sprachlichen Figuren; sie behandelte diese Themen also aus einem normativen Blickwinkel. Die Überlieferung besagt, daß die Rhetorik in Syrakus entstand und als ersten Erfolg die Versammlung der Bürger Athens von einem Bündnis überzeugte, das in einem verheerenden Feldzug endete. ${ }^{2}$ Von den Sophisten erwarb die Rhetorik den Ruf, selbst unklugen Vorschlägen noch zur Annahme verhelfen zu können und ihre Schüler dazu zu befähigen, sich vor der Öffentlichkeit erfolgreich zu verteidigen. In einem seiner Dialoge, im „Phädrus", widersetzte sich Plato den Lehren der Rhetorik. Er karikierte die Bereitschaft der Sophisten, jeden beliebigen Standpunkt - ganz gleich, ob er es verdiente - argumentativ zu vertreten, und lobte statt dessen die Philosophen, die als Freunde der Weisheit versuchten, sich der Wahrheit von Argumenten im Dialog zu nähern. Ob das Kriterium nun (korrekte und überzeugende) Form oder (absolute) Wahrheit hieß - die Fähigkeit, mit Argumenten richtig umgehen zu können, wurde in jedem Falle zum

2 Werner ErSENhut: Einführung in die antike Rhetorik und ihre Geschichte. Darmstadt 1974, S. 19. 
Kernstück eines „sophistizierten“ Verständnisses von Sprache. Der Schwerpunkt lag dabei auf dem Herstellen überzeugender Mitteilungen. Die Beziehungen zwischen den Kommunikationspartnern, die beteiligten kognitiven Prozesse und das Aushandeln von Bedeutung blieben unreflektierte Gegebenheiten.

Abb. 4: Japanische Schriftzeichen für "Kommunikation“"
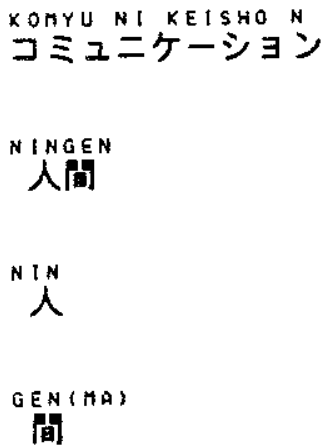

\section{MANUKE
周技け}

- Historisch gesehen, war das Bewußtsein für Kommunikation nicht nur in westlichen Kulturkreisen gering ausgebildet. Das Wort „Komyu-ni-ke-shon“ ist erst kürzlich in die japanische Sprache eingeführt worden. Viele Japaner können es zwar lesen, benutzen diesen Ausdruck aber nur selten. ${ }^{3}$ Überlieferte japanische und chinesische Schriftzeichen, in die der westliche Begriff der Kommunikation übersetzt wird, sind recht spezifischer Natur und erfordern genaue Bezugnahmen auf die konkreten Objekte, die gegeben, empfangen oder ausgetauscht werden. Bei der Suche nach alten Kommunikationsvorstellungen hat Shutaro MukAI die Aufmerksamkeit auf das geschriebene Wort „Nin-gen“ für "Mensch" gelenkt. ${ }^{4}$ Das Wort besteht aus zwei getrennten Schriftzeichen: "Nin“, das einer abstrakten menschlichen Figur ähnelt und ,jemand“, ,einer“, etwa wie in „man“ (liest ...) bedeutet, aber nie allein verwendet wird; und „Gen" oder „Ma“, was „Zwischen-“ (in Raum und Zeit) bedeutet. Demzufolge ist im Japanischen ein Mensch jemand mit Zwischenraum/zeit. Bemerkenswerterweise ist jemand ohne Zwischenraum/zeit (geschrieben "Ma-Nuke") ein Geistesgestörter. "Ma“ ist zudem ein Zeichen, das aus zwei Bildern zusammengesetzt ist: einem Tor, einem von Menschen geschaffenen Gebilde also, das geöffnet oder geschlossen werden kann, um Dinge oder Personen einzulassen oder ihnen den Zugang zu verwehren, und einer Sonne, einem natürlichen Gegenstand. Daher ist es naheliegend, das japanische „Ma“ als eine archaische Form unseres heutigen Kommunikationsbegriffs zu sehen. Zweifellos benennt es eine räumliche und zeitliche Beziehung, die man als grundlegend für menschliche Individuen sieht, eine Beziehung, deren Abwesenheit jemanden zu etwas anderem als einem Menschen macht, zu jemandem, der nicht fähig ist zu denken, der sich nicht verständlich machen kann und damit letztlich unfähig ist, das zu besitzen, was ihn zum menschlichen Individuum macht: Sprache kommunikativ zu gebrauchen. Man könnte gar sagen „Kommunikation ist Ma“ - oder war dem zumindest ähnlich.

Kommunikation ist ein Prozeß, der nur wenige physikalische Spuren hinterläßt. Deshalb ist es schwierig, aus der Überlieferung zu rekonstruieren, wie die

3 Youichi Ito: A Non-Western View of the Paradigm Dialogues. In: Brenda Dervin u.a. (Hrsg.): Rethinking Communication. Bd. 1: Paradigm Issues. Newbury Park 1989, S. 174.

4 Shutaro MUKaI: Zwischen Universalität und Individualität. Semiosis 1/1979, S. 41-51. 
Praktiken menschlichen Zusammenlebens konzipiert wurden, wie Menschen fruher ihre soziale Welt sahen oder in welcher Form sie miteinander kommunizierten. Auch aus diesen Gründen ist die vorangegangene Beschreibung der alten Vorstellungen von Kommunikation weder vollständig noch historisch exakt. Doch obwohl das Bewußtsein vom Kommunizieren eine sehr junge kulturelle Erfindung darstellt, lassen sich Spuren von Monumenten, Symbolon, Argumenten und „Ma“ in unseren zeitgenössischen Vorstellungen von Kommunikation wiederfinden.

Aufgabe 2 Charakterisieren Sie alte Kommunikationsvorstellungen.

\subsection{Die Metapher der Übertragung von Botschaften}

Ansatz 2 Jemanden durch einen weltlichen Boten benachrichtigen zu lassen, war sicherlich auch eine in der Antike übliche Praxis. Aber die Vorstellung von einer Botschaft als physikalischem Ereignis, das von einem Punkt zu einem anderen getragen werden konnte, war gewiß nicht vor der Erfindung des Papyrus und des Papiers möglich. Das Schreiben auf diesen leicht transportierbaren Medien erweiterte den archaischen Begriff des göttlich inspirierten Boten, indem er auf weltliche Personen anwendbar wurde und auf wesentlich ältere Erfahrungen mit dem Handel von Bernstein, Gewürzen und Gold zurückgriff. Damit wurde Kommunikation auf das Problem des Transports von Botschaften eingeengt. Die handgeschriebene und übertragene Botschaft lieferte überdies eine einzigartige - wie man heute sagt technologische Lösung für das individuelle Problem des unzuverlässigen Gedächtnisses und für das soziale Problem absichtlich verzerrter Darstellungen. Die Fähigkeit und der Wille, sich an die Inhalte einer Botschaft exakt zu erinnern und sie am Zielort genau wiederzugeben, setzten beträchtliche geistige Fertigkeiten und ein Vertrauensverhältnis zum Auftraggeber voraus. Mit der tragbaren Schrift änderte sich all dies.

Die Idee einer zu verschiedenen Orten tragbaren und damit „übertragbaren“ Botschaft war wohl die einflußreichste Erfindung in der Geschichte der Kommunikation. Ähnlich wie bei der Erstellung von Monumenten, doch im Unterschied zu den göttlich inspirierten Boten der mündlichen Tradition, gewann die geschriebene Botschaft nun eher objektive Qualitäten. Die Botschaften konnten von vielen gelesen, wiedergelesen und auch aufbewahrt werden. Die ehemals subjektiven Bedeutungen konnten auf die Schriftzeichen so projiziert werden, daß sie zu objektiven Inhalten wurden, die Übertragungsverluste undenkbar machten. Geschriebene Botschaften dienten als Ausdruck der Absichten ihres Absenders. Sie konnten kopiert und verglichen werden. Sie gaben den Anstoß für soziale Institutionen, die sich etwa dem Erhalt religiöser Texte widmeten. Sie förderten 
frühes wissenschaftliches Interesse am Austausch von Kalendern, Berechnungen und experimentellen Ergebnissen. Anders als Monumente konnten Botschaften chiffriert werden, um unbefugtes Lesen zu verhindern. Briefe und schriftliche Verfügungen förderten neue Formen der Verwaltung, die beispielsweise bei der Expansion des Römischen Reiches halfen. Sie ersetzten das Reisen, begründeten neue Gemeinschaften (etwa die der Wissenschaftler), dokumentierten Geschichte und schufen historisches Bewußtsein. Der Begriff der Botschaft bewirkte eine Vielzahl technologischer Erfindungen. Er führte, um nur einige Folgen zu nennen, zum Berufszweig des Schreibers, machte Bibliotheken möglich, perfektionierte die Entwicklung von Straßennetzen und ließ ein Postwesen mit einer technischen und personellen Infrastruktur von Austrägern, Postwegen und Gebührentarifen entstehen.

Die Metapher der übertragbaren Botschaft uberlebte zahlreiche technologische Revolutionen. Sie paßte sich dem Buchdruck, dem Pressewesen, dem Telegrafen, dem Telefon, dem Radio und Fernsehen ebenso an wie dem Computer: Botschaftsübertragung auf elektronischem Wege. Im Zuge dieser Anpassung aber geriet das Wort „Botschaft“, das anfänglich für „Auftrag“ und später für eher konkrete physikalische Objekte stand, welche die Spuren des Schreibens bewahrten, zur Metapher für das, was ,wirklich" in einem nicht länger berührbaren und sichtbaren Medium übertragen wird. Wir sprechen von elektronischen Botschaften, die man nicht mehr anfassen kann. Wir kaufen Anrufbeantworter, die Botschaften „aufbewahren“, die ein Anrufer uns „geben“ wollte. Wir sagen, wir haben eine Botschaft "nicht mitbekommen“, wenn wir meinen, daß wir etwas nicht verstanden haben. Wir bitten jemanden, eine persönliche Nachricht zu ,hinterlassen", die nur einen bestimmten Adressaten angeht. Wir wenden statistische Techniken auf Presseerzeugnisse, Radio- und Fernsehprogramme an und glauben, damit ihre Inhalte beschrieben zu haben. Wenn wir gefragt werden, was die Botschaft einer Predigt, einer politischen Rede oder eines Spielfilms war, so erwarten wir als Antwort eine Wiedergabe des Wesentlichen und keinen Bericht über die zufälligen Umstände des Kommunizierens.

Die technische Erfindung der transportierbaren schriftlichen Botschaft löste gewisse menschliche, soziale und spirituelle Probleme. Sie objektivierte, was anderenfalls zu erinnern gewesen wäre, und reduzierte damit das Kommunikationsproblem auf ein Transportproblem. Das nunmehr zur Metapher gewordene Übertragen von Botschaften behält diese Objektivität insofern bei, als es keine Bezugnahme mehr auf menschliche Fähigkeiten erfordert. Es erweitert die Idee der Übertragung auf das Übersetzen von Mustern von einem Medium zu einem anderen. Wie später klar werden soll, ist diese Metapher in die Asymmetrie zwischen einem aktiven, informierten Sender und einem passiven, unwissenden Empfänger eingebettet.

\section{Die Container-Metapher}

6.3.

Wesentlich für die Konzeption des göttlich inspirierten Boten war die UnterscheiAnsatz 3 dung zwischen dem Boten selbst und dem, was zu übertragen er beauftragt war. Nachdem der menschliche Träger einer schriftlichen Botschaft nicht länger mit dem zu tun hatte, was die Botschaft besagte, sondern nur damit, sie an ihr Ziel zu bringen, wurde nun auch eine Unterscheidung nötig zwischen der materiellen Form einer Botschaft und ihren Bedeutungen. Die materielle Form beeinflußte die (Über-)Tragbarkeit, was man von den Bedeutungen hingegen nicht sagen konnte. Vielleicht war es nur die Analogie zwischen Briefen, die in einer Schatulle einschließbar waren, und Schriftzeichen, denen man Bedeutungen "mitgeben" konnte, um sie gegen unberechtigte Einsichtnahme zu schützen, die zu der heute weit verbreiteten Metapher von der „Botschaft als Container“ (Behälter) führte. 
Von einigen Kommunikationsforschern wird diese Metapher spaßeshalber auch „Kübeltheorie der Bedeutung“ genannt. Doch sollte sie sehr viel ernster genommen werden, denn sie durchzieht praktisch die gesamte heutige Diskussion über Kommunikation. Wir fragen jemanden, was „in“ einem Brief steht, was er „aus“ einem Vortrag ,entnommen" hat, oder wir beklagen, daß jemand etwas ,in" eine Botschaft hineinliest, was nicht ,in“ ihr ,enthalten“ ist. Noch mehr im Sinne des Wortes untersuchen wir den "Inhalt" einer Fernsehsendung, beurteilen einen Satz als bedeutungs,,voll" oder ,voller“ Bedeutung, erklären, ein Artikel sei mit Ideen "gefüllt", oder behaupten, er „enthalte“ gar nichts Neues. Wir nehmen leicht an, daß jemand, der sein Herz nicht "in" das legt, was er sagt, nichts auszusagen habe. In ähnlicher Weise sprechen Ingenieure davon, daß Signale Informations, ,gehalt" haben oder durch Rauschen verschmutzt oder überlagert werden. Solche Ausdrucksweisen machen Botschaften, sprachliche Ausdrücke, Bilder und elektronische Signale zu Containern für Bedeutungen, Ideen oder Dinge, die darin aufbewahrt, an ihren Bestimmungsort verfrachtet und anschließend wieder entnommen werden können.

Die Container-Metapher hat zur Folge, daB die Botschaft und ihr Inhalt Einheiten (,Entitäten“) unterschiedlicher Art sind. Für den Container mag dies noch offensichtlich sein. Das Papier, auf dem etwas geschrieben steht, das elektronische Signal oder der Schall einer Stimme haben eine physikalisch meßbare Existenz. Die Metapher legt aber nahe, auch Sinn und Bedeutungen als Entitäten aufzufassen. Ein Studienkurs bringt uns ,etwas"; wir erhalten Bruch,,stiicke“ einer Information oder „Teile" einer Nachricht; manchmal glauben wir, jemand habe uns nur die "halbe" Wahrheit gesagt. Obwohl wir davon überzeugt sind, daß wir Bedeutungen nicht an einen Baum nageln können, haben wir keine Bedenken, Schilder, Warnungen und Bekanntmachungen an Straßenecken oder auf Litfaßsäulen anzubringen, womit wir deren unterschiedliche Bedeutungen als unterschiedliche Objekte behandeln. Die Container-Metapher legt daher nahe, Bedeutungen nicht viel anders zu analysieren als ein Geologe, der verschiedene Gesteinsbrocken in unterschiedliche Kästen sortiert.

Da Botschaften demnach Entitäten beinhalten können, liegt es nahe, sich auch Container in Containern vorzustellen. So werden Wörter zu Behältern von Ideen, Briefe zu Behältern von Wörtern, Umschläge zu Behältern von Briefen, die wiederum in Säcken verschickt werden können. Die jeweils enthaltenen Entitäten werden damit zum Zweck der Kommunikation und deren Container ihr Mittel, womit letztlich die Kommunikation als ein linear verlaufender Prozeß gedacht wird. Im Militärwesen wird übrigens „Kommunikation“ immer noch gleichgesetzt mit Transport, Straßenbau und logistischer Unterstützung der Truppen, damit die Botschaft ihr jeweiliges Ziel erreicht.

Wie stark sich die Metapher "Botschaften als Container für Entitäten“ festgesetzt hat, sieht man besonders in den Erklärungen, die gegeben werden, wenn die Implikate der ihr innewohnenden Logik versagen: Wenn eine Botschaft Entitäten enthält, die jemand absichtlich dort hineingelegt hat, so sollte daraus folgen, daß ihr Empfänger sie genau so wieder entnimmt. Sollte er ihr aber etwas anderes entnehmen, so muß nach dieser Logik entweder ein Fehler auf dem Übertragungsweg vorliegen, oder der Empfänger ist inkompetent, hinterhältig oder gar verrückt. Die Möglichkeit, daß die dieser Logik zugrundeliegende Metapher unangemessen ist, wird nur selten bei der Schuldzuweisung für solche Ungereimtheiten in Betracht gezogen. Die Implikate dieser Metapher sind natürlich problemlos, wenn Kommunikation gelingt. Für den zweiten Leser einer Zeitung führen sie jedoch schon zu Widersprüchen, weil die Inhalte eben nicht als entfernt oder vom ersten Leser verbraucht erfahren werden. Trotz solcher physikalischen Absurditäten, zu denen die Container-Metapher letztlich führt, wird sie dennoch weitgehend aufrechterhalten. 
6.4 .

Ansatz 4

Gemeinsamkeit wird“, sie gleich macht oder gleichartig denken läßt, folgt logisch aus der Metapher, nach der Botschaften "Container für Entitäten" sind. Sie könnte schon in der alten Vorstellung des Symbolon vorweggenommen worden sein und ist auch im Begriff der Mitteilung enthalten.

Das englische Wort „sharing“ hat zwei recht unterschiedliche Bedeutungen: Die erste meint „Teil eines höheren Ganzen sein“, „eine Rolle in einem größeren Zusammenhang spielen". Die zweite, und auf diese beziehen wir uns im folgenden, meint ,etwas mit jemandem gemeinsam haben“, ,jemand anderem in bestimmter Hinsicht zu gleichen“, "gleich denken und handeln“. Letztere Gemeinsamkeit kann anhand der bekannten Vennschen Diagramme leicht verdeutlicht werden. Ein solches Diagramm zeigt mindestens zwei sich überlappende Kreise, die unterschiedliche Elemente enthalten. Die Überschneidung der beiden Mengen enthält nur solche Elemente, die beiden Mengen gemeinsam sind; die jeweilige Restmenge umfaßt dann nur noch solche Elemente, die der einen, nicht aber der anderen Menge zugehören.

$A b b$, 5: Darstellung der Schnittmenge (schraffierte Fläche) im Venn-Diagramm

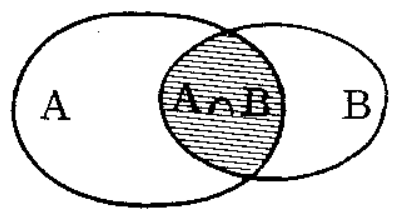

Wenn man das Versenden und Empfangen von Botschaften als das Ein- und Auspacken von Entitäten an unterschiedlichen Orten sieht, liegt es nahe, erfolgreiche Kommunikation an folgende Bedingungen zu binden:

- Was auch immer versandt wird, muß identisch empfangen werden.

- Die Absichten eines Kommunikators werden vom Empfänger einer Mitteilung direkt, also ohne Interpretation, aufgenommen.

- Wenn zwei Personen dieselbe Mitteilung erhalten, können sie ihr auch denselben Inhalt entnebmen.

- Im Falle von Massenkommunikation werden all diejenigen, die demselben medialen Ereignis ausgesetzt sind, über denselben Zeichenvorrat verfügen, dieselben Regeln und Konventionen benutzen, dieselben Inhalte aufnehmen, über dieselben Sachverhalte informiert, dieselben Mediensozialisationsprozesse durchlaufen, dieselben Weltvorstellungen entwickeln, dieselben Wertvorstellungen vertreten - kurz gesagt, sie werden gleichartig denken und finden sich innerhalb der Schnittmenge eines Venn-Diagramms repräsentiert.

Demnach schafft Kommunikation Gemeinsamkeiten oder informiert ihre Teilnehmer. Schon der unschuldig gebrauchte Begriff „Mitteilung“ ist ein Ausdruck dieser Metapher. Während eine Botschaft über deren Träger nichts Wesentliches aussagt, ist eine Mitteilung immer ein Mittel, etwas mitzuteilen (und zwar nicht im Sinne von "Anteil" haben oder ein größeres Ganzes ,aufteilen“, sondern) im Sinne von „etwas gleiches gelesen“ zu haben, „über das gleiche informiert zu sein“, „gemeinsames Wissen" zu besitzen oder einfach "mitzuwissen“. Obwohl man sich leicht vorstellen kann, daß eine einzige Nachricht sehr verschiedene Aussagen machen und Interpretationen hervorrufen kann (insbesondere für unterschiedliche Empfänger), macht die Metapher des Mitteilens von Gemeinsamkeiten eine Mitteilung zu einer Nachricht, die den beteiligten Kommunikationspartnern das gleiche sagt, also in der Schnittmenge eines Venn-Diagramms zu finden ist.

Was außerhalb der Schnittmenge liegt, das heißt die den Kommunikationspartnern nicht gemeinsamen Inhalte, muß demnach ein Irrtum sein: Bedeutungen, die in eine Botschaft hineingelegt, aber nicht in der gleichen Weise herausgenommen 
wurden, oder Bedeutungen, die einer Botschaft entnommen wurden, aber in ihr gar nicht vorhanden waren. Außerhalb der Schnittmenge liegen die Zeichenrepertoires, welche die jeweils anderen nicht verstehen können, die demnach Kommunikation verhindern. Diese Restmengen eines Venn-Diagramms tragen also nichts dazu bei, Sprachgemeinschaften, soziale Gruppen oder kulturelle Gemeinsamkeiten, mögliche Zeichen, Bedeutungen oder Inhalte hervorzubringen. Deshalb werden diese Restmengen entweder als theoretisch unerhebliche Subjektivität ignoriert, als Idiosynkrasien abgeschrieben oder als Abweichungen, Verzerrungen oder Fehlschläge gebrandmarkt.

Belege für die Wirksamkeit dieser Metapher finden sich im Überfluß. Bei Gerichtsverhandlungen mag ein Richter darauf achten, daß die Unterzeichner eines Dokumentes der benutzten Sprache mächtig sind; er wird aber kaum daran zweifeln, daß es nur eine korrekte Lesart des Dokumentes gibt. Viele Inhaltsanalysen von Massenkommunikationsprodukten beanspruchen, ein objektives Bild davon zu zeichnen, was im Fernsehen, in Radiosendungen oder in der Presse der Öffentlichkeit präsentiert wird, als ob es nur eine korrekte Interpretation gäbe, die jeder kompetente Zuschauer oder Leser allein finden kann und danach völlig versteht. Die im Rahmen der Kommunikationsforschung weit verbreitete Annahme, man könne den Inhalt einer Botschaft objektiv (also ohne Bezug auf Sender oder Empfänger) analysieren, macht es gleichsam unnötig, danach zu fragen, wie Bedeutungen aus dem Kopf des einen Menschen in eine Botschaft umgesetzt werden und schließlich in den Kopf eines anderen Menschen gelangen können. Damit umgeht man Aspekte der menschlichen Kognition und reduziert die Frage, wie jemand etwas interpretiert, darauf, welchen Nachrichten er objektiv ausgesetzt war.

Abb. 6: Kommunikation als Erzeugung und Mitteilung von Gemeinsamkeiten

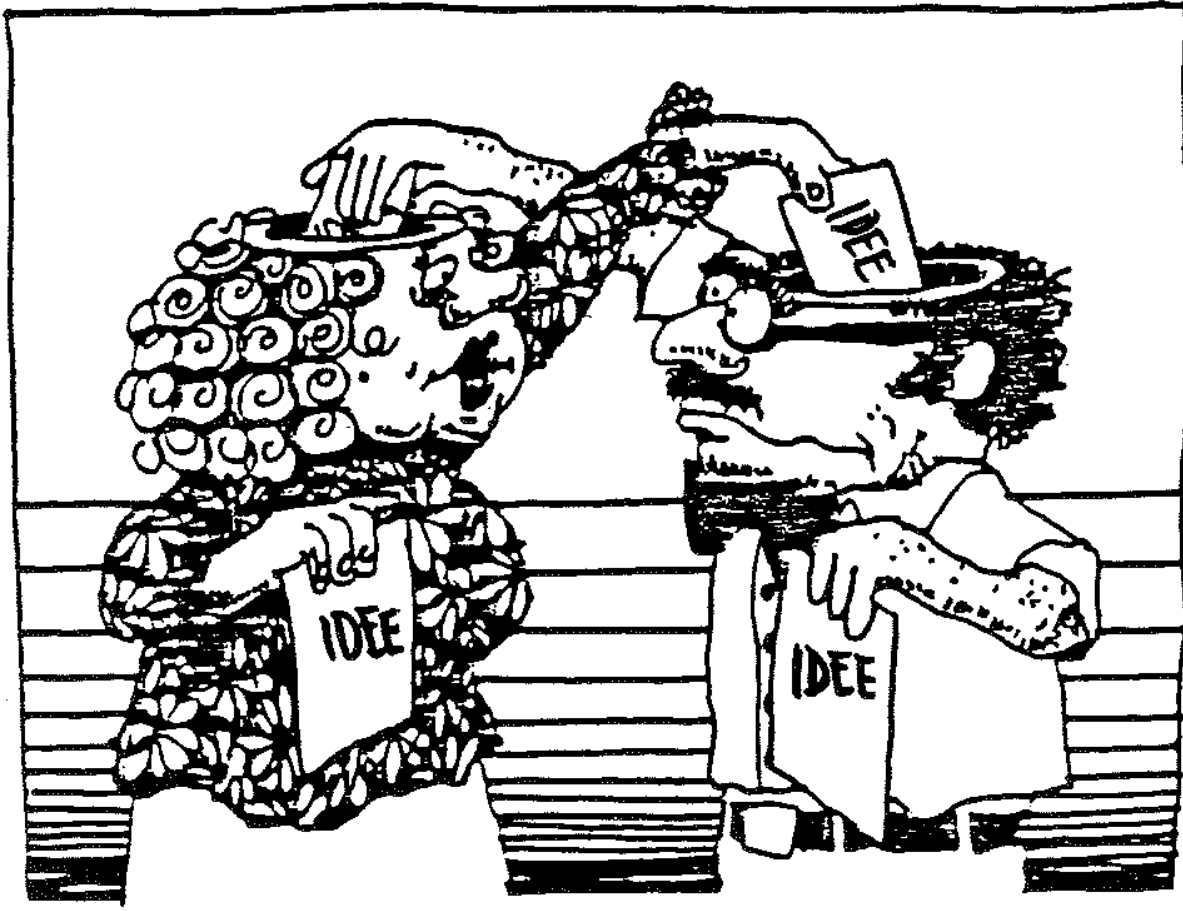

Im Alltagsleben ist die Vorstellung von Kommunikation als dem Herstellen kognitiver Gemeinsamkeiten noch sehr viel mehr zu Hause. Man denke an solch übliche Fragen wie: „Hast du verstanden, was (es ist, das) ich gesagt habe?“, „Hast du $e s$ kapiert (auf den Inhalt des Gesagten verweisend)?“, „Versprechen diese beiden Politiker dasselbe?“, „Können wir dem zustimmen?“, ,Haben wir denselben 
Background (die gleichen Erfahrungen durchlaufen)?" Alle diese Fragen setzen voraus, daß es nur eine legitime Bedeutung gibt, die jeder kompetente Kommunikationspartner auf natürliche Weise durch bloßen Kontakt mit der vorhandenen Mitteilung begreift. Der objektive Status des allen Beteiligten gemeinsamen Inhalts von Mitteilungen wird uberhaupt nicht in Frage gestellt.

Die Popularität dieser Metapher zeigt sich auch in der Bedeutungsgeschichte des Wortes „Kommunikation". Es hat immerhin dieselbe Wurzel wie „Kommune“, „Kommunion", „kommunal“ oder gar „kommunistisch“, die allesamt etwas mit „Gemeinsamkeit“ zu tun haben und auf gleiches Denken, ähnliche Erfahrungen oder gemeinsame Geschichte ihrer Teilnehmer hinweisen. Auch das alte Symbolon, welches das Teilen gemeinsam erfahrener Freundschaft in den zwei Hälften einer Münze repräsentiert, gehört in diesen Zusammenhang.

Welche Vorstellungen von Kommunikation bringt die Metapher der „Mitteilung von Gemeinsamkeiten" zum Ausdruck?

\section{Die Metapher vom Argument als Krieg}

Aus dem oppositionellen Klima, dem die griechische Rhetorik entstammt, oder vielleicht auch gegründet auf die britische Tradition öffentlichen Debattierens, entstand eine Metapher, die vermutlich sehr viel enger am Sprechen als am Schreiben anknüpft und Kommunikation oder Argumentation als Kriegsführung sieht. Die amerikanischen Sprachwissenschaftler George LAKOFF und Mark JoHNSON haben gezeigt, daß diese Metapher in einer Vielzahl alltäglicher Redewendungen anzutreffen ist:

„, Ihre Behauptungen sind unhaltbar.

"Er griff jeden schwachen Punkt in meinem Argument an."

,Seine Kritik hat genau getroffen."

,Ich habe seine Argumente zunichte gemacht.

,Ich bin nie mit einem Argument gegen ihn durchgekommen.

,Du stimmst nicht zu? Dann schieß mal los!"

"Wenn du diese Strategie wählst, wird er dich fertigmachen."

"Er hat alle meine Argumente abgeschmettert."

Es ist sehr wichtig zu erkennen, daß wir mit Argumenten in der Sprache des Krieges nicht bloß reden. Argumente können wir tatsächlich gewinnen oder verlieren. Wir nehmen die Person, mit der wir argumentieren, als Gegner wahr. Wir attackieren seine Position und verteidigen unsere eigene. Wir gewinnen oder verlieren an Boden. Wir planen und benutzen Strategien. Wenn wir eine Position unhaltbar finden, können wir sie aufgeben und eine neue Angriffslinie aufbauen. Viele der Dinge, die wir beim Argumentieren tun, sind durch das Konzept ,Krieg teilweise strukturiert. Wenn es auch keine physischen Schlachten sind, so sind es doch verbale Schlachten, die sich in der Struktur des Argumentierens - Angriff, Verteidigung, Gegenangriff usw. - spiegeln. In diesem Sinne ist die Metapher ARGUMENT ALS KRIEG eine der Metaphern, von und mit denen wir in unserer Kultur leben. Sie strukturiert die Handlungen, die wir beim Argumentieren ausführen.
6.5.

Ansatz 5 
Stellen wir uns einmal eine Kultur vor, in der Argumente nicht im Sinne von Krieg gesehen werden, in der niemand gewinnt oder verliert, in der es keinen Sinn für Angriff oder Verteidigung, für das Gewinnen oder Verlieren an Boden gibt. Stellen wir uns eine Kultur vor, in der Argumente als Tanz und die Teilnehmer als Tänzer gesehen werden und das Ziel darin besteht, in einer ausgeglichenen, ästhetisch ansprechenden Weise zu tanzen. In einer solchen Kultur würde man Argumente ganz anders sehen, anders erleben, anders ausfuihren und anders über sie sprechen. Wir aber würden sie wahrscheinlich gar nicht als Argumentierende sehen; für uns würden sie einfach etwas anderes tun. Es schiene gar merkwürdig, das, was sie tun, ,Argumentieren' zu nennen. Die vielleicht neutralste Weise, den Unterschied zwischen ihrer und unserer Kultur zu beschreiben, bestünde darin zu sagen, daß wir eine Form des Diskurses haben, die im Sinne von Krieg strukturiert ist, und daß sie eine Form haben, die im Sinne von Tanz strukturiert ist."5

Sprachliche Kommunikation und bewaffnete Konflikte sind sicherlich wesentlich unterschiedliche Arten menschlichen Handelns. Übernimmt man aber die Metapher vom Argument als Krieg, so wird eine Kommunikationssituation zwangsläufig zum Konflikt, und die Kommunikationspartner werden gegeneinander gesetzt mit dem Ergebnis, daß sich jeder gegenüber dem anderen zu behaupten sucht, so daß am Ende nur einer gewinnen kann. Natürlich funktioniert diese Metapher am besten dort, wo es tatsächlich etwas zu gewinnen oder zu verlieren gibt, wie etwa beim Aushandeln eines guten Preises oder in einer Parlamentsdebatte. Wenn es aber kein offensichtliches Kriterium gibt für das, was gewonnen oder verloren werden kann, so zieht der Gebrauch dieser Metapher sogleich externe Einflüsse nach sich wie etwa Stolz, Dominanz, demonstrative Kompetenz usw. All diese Kriterien müssen nichts mit dem zu tun haben, was eigentlich zur Diskussion ansteht. Dennoch können sie häufig recht wirkungsvoll die Lösung der Probleme behindern, derentwegen die Menschen miteinander reden.

\subsection{Die Metapher vom Kanal oder: Der Fluß der Signale}

Ansatz 6 Das 19. Jahrhundert brachte der menschlichen Kommunikation eine neue Technologie. Frühe Experimente mit beständigen Elektrizitätsquellen im 1. Viertel des Jahrhunderts führten bereits im 2. Viertel zu kommerziell betriebenen Telegrafenlinien. Das Telefon wurde 1876 erfunden und war zur Jahrhundertwende bereits weit verbreitet. Die Geschwindigkeit dieses technischen Fortschritts war atemberaubend und ließ, außer bei wenigen Experten, das Verständnis dafür weit hinter sich zurück, wie Botschaften mit ihrer nicht zu leugnenden physischen Gestalt (Dimensionalität) denn durch massive Kabel gezwängt werden könnten. Diese Situation bietet ein perfektes Beispiel für den Bedarf an neuen Metaphern, die bekannte, erklärungskräftige Strukturen auf neue Erfahrungsbereiche beziehen, um Erscheinungen, die sonst unverständlich blieben, ordnen und verstehen zu können. Die Vorstellung, Botschaften müßten durch Kabel gezwängt werden, hängt mit einer Metapher zusammen, die aus der Hydraulik, vielleicht gar aus dem Schiffswesen stammt und sich rasch als vorherrschende Metapher für die Funktionsweise dieser neuen Technologie durchsetzte. Das Kabel der Telegrafenleitung konnte man als eine Röhre sehen, durch die etwas von einem Sender zu einem Empfänger floß, ganz ähnlich wie bei einem Rohrleitungs- oder Kanalisationssystem. Nun konnte man auf dem Telegrafenweg ursprünglich aber nur elektrisches Potential ein- und ausschalten und dadurch Punkte und Striche übermitteln, welche den Buchstaben des Alphabets entsprachen, und der Telefonweg war auf akustische Eingabesignale wie die der menschlichen Stimme beschränkt.

Diese technischen Beschränkungen der Telegrafie und des Telefons führten ganz natürlich zum Begriff des Kommunikationskanals, also zu einer Zerlegung des physikalischen „Spektrums“ in unterscheidbare „Flüsse“. Mit der nun etablierten

5 George LaKoff / Mark Johnson: Metaphors we live by. Chicago 1980, S. 4-5. 
hydraulischen Metapher von Kommunikation als einem rohrartigen Kanal fällt es leicht, menschliche Kommunikation als mehr-kanalige Erscheinung anzusehen, die gleichzeitig verbale und nichtverbale Kanäle wie auch solche des Sehens, Hörens, Berührens, Riechens und Schmeckens umfaßt. In der Massenkommunikationsforschung spricht man von "Schleusen“ (sog. gatekeeper), die den Informationsfluß hin zur Öffentlichkeit filtern und kanalisieren. In der Analyse von Kommunikation in sozialen Organisationen spricht man von „Engpässen“, die den Gesamtfluß beschränken. Um zu verstehen, wie Regierungsentscheidungen in einem komplexen Verwaltungsapparat verarbeitet werden, spricht man von langen oder kurzen "Wegen“. Man mißt das Kommunikationsvolumen, vergleicht es mit der Kanalkapazität und beklagt Überlastungen. Diese und andere geläufige Konzepte stammen ausschließlich aus der Hydraulik.

Abb. 7: Das Johnson-Modell

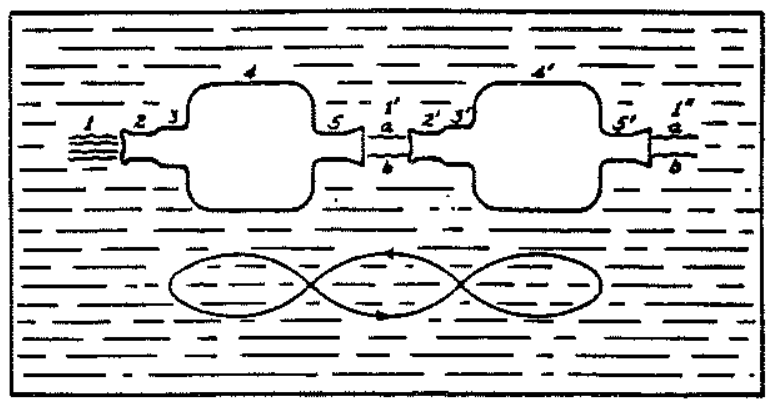

\begin{abstract}
Zustand 1: Ereignis oder Quelle der Stimulation (außerhalb der Sinne und Organe des Sprechers) Zustand 2: Stimulation der Sinne

Zustand 3: vorsprachlicher neurophysiologischer Zustand

Zustand 4: Übertragung vorsprachlicher Formen in symbolische Formen

Zustand 5: sprachliche Formulierungen in endgültiger Form für die Übermittlung

Zustand l': Übertragung sprachlicher Formulierungen in (a) Ätherwellen oder (b) Lichtwellen, die als Quellen der Stimulation für den Zuhörer dienen (der sowohl der Sprecher als auch eine andere Person sein kann).

Zustand $2^{\prime}$ : korrespondiert mit 1" wie Zustand 2 mit 1'. Die mit Pfeilen versehenen Schleifen stehen für die funktionalen Wechselbeziehungen aller Zustände in diesem Prozeß.
\end{abstract}

Aus: Wendell Jomnson: The fateful process of Mr. A. talking to Mr. B. Harvard Business Review 1/1953, S. 50.

Die Metapher vom Kanal, die wir unseren Erfahrungen mit den Fließeigenschaften von Flüssigkeiten verdanken, stellt uns vor die gleichen Probleme, denen wir schon bei der Übertragung von Botschaften begegneten: Wie konnte man das verstehen, was am anderen Ende Sinn machte, aber mit den durch den Kanal fließenden Flüssigkeiten nichts zu tun hatte? Die Erklärung der Physiker in Begriffen von Elektronenbewegung, wellenförmigen Modulationen, Quantenmechanik usw. waren allzu weit von den sozialen Konstruktionen entfernt, die das Verstehen von Kommunikation über Telefon, Radio oder Fernsehen leiteten. Selbst die Ingenieure mußten (oder konnten) sich nicht auf die Physik der Kommunikation einlassen. Sie entwickelten ein eigenes metaphorisches Verständnis des Signalverkehrs in den Kabeln: eine Vorstellung von Signalen, die Informationen durch den Kanal tragen und sich durch Störgeräusche verschmutzen lassen, als gäbe es objektive Unterschiede zwischen dem Signal und dem, was es mit sich trägt. Hier ist die Beziehung zwischen Behälter und Inhalt als eine Beziehung zwischen Träger und Getragenem wiederaufgegriffen.

Auch diese neuartige Objektivierung des Gesendeten läßt die kognitiven Leistungen von Sender und Empfänger außer acht. Sie beschritt nur wieder den bereits ausgetretenen Pfad gebräuchlicher Metaphern des Verstehens von Kommunikation. Obwohl es uns nicht möglich ist, Zeichen, Symbole, Bilder oder Botschaften in einem Fluß von Signalen zu unterscheiden und als solche zu erkennen, sprechen wir heute ohne Hemmungen von der Übertragung von Zeichen, Symbolen, Daten, Texten und Bildern durch Signale. Damit halten wir die Unterscheidung aufrecht zwischen Signal- oder Zeichenträgern, denen physikalische Eigenschaften zugeschrieben werden, und Zeichen, Symbolen oder Botschaften, von denen man glaubt, sie würden von den Signalen getragen - als ob das Medium schlau genug sei, sich ihrer Unterschiede anzunehmen, also wüßte, was sie sind und wie man sie behandeln muß. 


\subsection{Die mathematische Theorie der Kommunikation (Informationstheorie)}

Ansatz $7 \quad$ Bei der Erwähnung von Modellen und Metaphern der Kommunikation können wissenschaftliche Theorien nicht ausgeschlossen werden. Denn auch diese Theorien werden sprachlich formuliert, handeln von Kommunikationsprozessen und richten sich häufig an genau die gleichen Personen, deren kommunikative Praxis sie zu beschreiben oder zu modellieren suchen. Diese Personen können sich aber den Theorien widersetzen, das Gegenteil des theoretisch Vorhergesagten tun, mit ihnen übereinstimmen oder sie als Standard für ihr eigenes Verhalten nehmen. Auch können sie die Entwickler von Kommunikationstheorien für die Veröffentlichung ihrer Theorien zur Rechenschaft ziehen und sie auffordern, die Verantwortung für deren Konsequenzen zu übernehmen. Wissenschaftliche Kommunikationstheorien etablieren sich folglich durch die kommunikative Praxis, die sie in einem Medium bewirken.

Kurz nach Beendigung des Zweiten Weltkriegs erschien Claude E. SHannons und Warren WeAVERs ", The Mathematical Theory of Communication ". ${ }^{6}$ Im Grunde ist dies eine Theorie, die es gestattet, die Informationsmengen so zu quantifizieren, $\mathrm{da} \beta$ man sie als zwischen und innerhalb von Systemen übertragene Mengen interpretieren kann, gleich ob es sich um mechanische, biologische oder soziale Systeme handelt. Solche Quantifizierungen ermöglichten es, Informationsflüsse ähnlich denen des Geldes innerhalb eines Konzerns oder denen der Energie in einer Stadt darzustellen. Sie beziehen sich aber auf eine gänzlich andere Art von Quantitäten, nämlich auf Informationsmengen, die man in „bits“ mißt.

Das Problem, das Volumen dessen zu messen, was durch Übertragungskanäle fließt oder fließen könnte, wurde eindeutig unter dem Eindruck der Metapher vom Kanal formuliert, und SHANNONS Erklärungen tragen deutlich deren Spuren. Für die Gewinnung von Informationsquantitäten in seinem Programm erwiesen sich jedoch die gerade diskutierten Metaphern und die mit ihnen verbundenen Konzepte als weitgehend ungeeignet und irreführend. SHANNON selbst hat von sich aus davon abgesehen, den Begriff „Informationstheorie“ zu verwenden. Denn er befürchtete, daß die quantitativen Begriffe, die er aus seinen Axiomen ableitete, nicht mit populären Begriffen von Information im Sinne benötigten Wissens, das man von einem Produzenten zu einem Konsumenten schicken könnte, harmonierten und daß der Gebrauch unvereinbarer Metaphern oder Begriffe die praktischen Anwendungen seiner Theorie erschweren würden. Dementsprechend hat er sich ausdrücklich nur damit beschäftigt, wieviel von einem Ort zu einem anderen kommuniziert werden kann (Kanalkapazität) und wird (Übertragungsmenge) und inwiefern die Natur der Encodierungs- und Decodierungsprozesse, einschließlich der Übertragungsfehler, in solchen quantitativen Begriffen beschreibbar ist und die übertragbaren Informationsquantitäten begrenzt.

Ein großer Teil der Theorie beruht auf der Vorstellung, daß Information jemanden befähige, über puren Zufall hinaus geeignete Unterscheidungen bzw. Auswahlen zu treffen oder zwischen Alternativen wählen zu können, deren Wahrscheinlichkeiten zumindest langfristig erkennbar sind. Ähnlich dem Energiekonzept in der Physik, das nicht in bezug auf spezielle Energieformen, sondern als Maß mechanischer Arbeit definiert ist, bestimmt sich Information hier weder als Bedeutung noch als Materie. Es ist ein Maß für die logische oder intellektuelle Arbeit, die eine Mitteilung im Zusammenhang des als möglich Erwarteten leisten kann. Logische oder intellektuelle Arbeit bezieht sich hier auf das Unterscheiden, das Fällen von Entschlüssen, das logische Verknüpfen und Organisieren oder

6 Claude E. SHANNON / Warren WEAver: Mathematische Grundlagen der Informationstheorie. München/Wien 1976. (Zuerst 1949: The Mathematical Theory of Communication. Urbana.) 
Reproduzieren von Verhaltensmustern und Kommunikation ermöglicht es, diese Arbeit über eine Distanz hinweg zu verrichten, zeitlich aufrechtzuerhalten oder in verschiedene Formen und unter dem Einfluß zufälliger Störungen (Rauschen) zu übersetzen.

Historisch gesehen lieferte SHannons Theorie quantitative Begriffe, wie Informationsübertragung, Kanalkapazität, Redundanz, Äquivokation und Rauschen - ein Vokabular, das sich rasch in vielen Disziplinen ausbreitete. Unter dem Einfluß dieser Theorie wurde beispielsweise der Computer nicht länger als bloße Addiermaschine gesehen, sondern als Logikmaschine, von der man meinte, sie könne Entscheidungen treffen und Informationen verarbeiten. Organe, insbesondere das menschliche Gehirn, wurden nun beschrieben als komplexe Nervensysteme zur Informationsverarbeitung. Hören, Denken und Sprechen wurden dargestellt als die Encodierung und Decodierung signifikanter Muster (als Vorstellungen im Nervensystem). Bibliotheken wurden zu Depots gesellschaftlicher Information, zu Sammelstellen des Wissens, das eine Kultur zu unterstützen in der Lage ist. Regierungen wurden zu politischen Informationsverarbeitungssystemen. SHANNONS Theorie - rigide, wie sie ist, und in ihren Zielen auf abzählbare Alternativen und damit verbundene Wahrscheinlichkeiten angewiesen - hat heute die Kraft einer Metapher erreicht, die die verschiedensten empirischen Erfahrungsbereiche organisiert und die wissenschaftliche Grundlage für die Erforschung menschlicher Kommunikation bildet. Aus diesem Grund haben wir die Informationstheorie hier in einen Zusammenhang mit den „volkstümlichen Theorien der Kommunikation" gebracht.

SHANNONS Arbeit hatte einen besonders entscheidenden Einfluß auf die moderne Kommunikationstechnologie. Die Quantifizierung von Information erzeugte das Bewußtsein ebenso wie die Fähigkeit, die Möglichkeiten der alten Medien optimal auszunutzen und neue Medientechnologien, vom UKW-Radio bis zur GlasfaserTechnologie (ISDN), zu erfinden. Die Idee der Informationsverarbeitung führte zur Entwicklung neuer Codes für die Informationsübertragung zwischen den verschiedensten Systemen einschließlich zwischen natürlichen und künstlichen Sprachen. Die Vorstellung von Übertragung wurde zunehmend unabhängig vom physikalischen Medium und statt dessen gekoppelt an die Vorstellung miteinander verbundener Muster. In dem Maße, in dem die technisch vermittelte Kommunikation einfacher und billiger wurde, konnten immer mehr Menschen durch weitausgedehnte Netzwerke miteinander in Verbindung kommen, um Zugang zu Informationsquellen zu gewinnen oder um gemeinsame Handlungen über beliebige Entfernungen hinweg zu koordinieren. Ihr Handeln wurde damit um eine Vielfalt von Wahlmöglichkeiten erweitert, die zuvor nicht bestand. Die Theorie beschleunigte somit nicht nur die technische Entwicklung, sondern sie wurde auch zum Eckpfeiler zahlreicher neuer wissenschaftlicher Disziplinen, von der bereits erwähnten Kommunikationsforschung bis zur Künstlichen Intelligenz. Sie leitete damit die Entstehung einer, wie manche behaupten, neuen Gesellschaftsform ein, die nicht in erster Linie durch Energie- oder Rohstoffquellen vorangetrieben wird, sondern durch Information.

Welche Erscheinungen werden mit der mathematischen Informationstheorie SHANNONS angemessen beschrieben? Welche Wirkungen gingen von diesem Konzept aus? 


\subsection{Die Kontroll-Metapher}

Ansatz 8 Sehr alt ist auch die metaphorische Gleichsetzung von Kommunikation mit Kontrolle, die Vorstellung, der Mensch müsse sich seine Umwelt zum Untertan machen. Was zwischenmenschliche Beziehungen betrifft, geht die KontrollMetapher mindestens auf die antike Sophistik zurück, in der überzeugende Argumentation höher gewichtet wurde als Wahrheit. Die Beherrschung der Natur, das Bedürfnis, angestrebte Ziele zu erreichen, die Suche nach technologischen Lösungen menschlicher Probleme, instrumentelle Rationalität im weitesten Sinne scheinen heute, zumindest in der technologisch fortgeschrittenen westlichen Welt, zum Selbstzweck geworden zu sein. Auch Konzeptionen von Kommunikation werden dăher von dieser instrumentellen Vorstellung aufgesogen. Flankiert wird die Kontroll-Metapher von mehreren Begriffen, die Kommunikation als Quelle von Macht, als Technologie der Beherrschung und Manipulation oder als Steuerung ausgeben.

In der Alltagssprache finden sich genügend Beispiele, die zeigen, daß Kommunikation als kausales Phänomen verstanden wird. So sagt man: „Der Wetterbericht veranlaßte sie, ihren Regenmantel anzuziehen“, „Der Brief, den ich bekommen habe, machte mich gliicklich", "Die Massenmedien haben das Wahlergebnis beeinflu $\beta t^{\prime,}$, ,Fernsehen wirkt sich auf die Schulleistungen $a u s^{\prime \prime}$, "Ein rassistischer Werbespot verursachte eine Welle von Beschwerden“", Der Bericht zwang das Management, seinen Standpunkt zu überdenken". Wo Kommunikation als Abfolge von Ursache und Wirkung verstanden wird, ist man gezwungen, nach den Kräften zu suchen, die solche Wirkungen auszulösen vermögen. Man spricht demgemäß von überzeugenden Rednern, von starken Anreizen, wirkungsvollen Nachrichten oder durchschlagenden Argumenten und besteht darauf, daß diese Kräfte zusammen mit der Nachricht vermittelt werden oder in ihr selbst liegen und nicht vom Rezipienten einer Botschaft aufgebracht werden müssen. Ein Großteil der wissenschaftlichen Forschungsarbeiten zur Kommunikation ist um kausale Verbindungen zwischen Botschaft und Wirkung bemüht, sei es, daß die Auswirkungen neuer Technologien erfragt werden oder die Reaktionen des Publikums auf einen Politiker untersucht werden. Natürlich gibt es auch andere Erklärungsrahmen, um beispielsweise die Frage zu beantworten, warum jemand keinen Regenmantel überzieht, obwohl er den warnenden Wetterbericht gehört hat. Aber kausale Begründungen sind eben nicht nur viel einfacher zu verstehen: sie liefern auch institutionell bevorzugte Erklärungen. Was sich nicht ursächlich erklären läßt, ist als Instrument oder Mittel zur Erreichung eines Ziels unbrauchbar. Ziele zu erreichen ist ein wesentlicher Bestandteil zweckrationalen Denkens.

Die gesamte Kommunikationsindustrie und besonders die Massenmedien sehen Kommunikation nahezu ausschließlich als Mittel, um etwas aus der Distanz zu bewirken, das heißt als Manipulationstechnologie, durch die ein Produkt verkauft, ein Politiker ins Amt gesetzt oder die Bürgerschaft zum Handeln aufgerufen werden sollen. Diese instrumentelle Konzeption von Kommunikation spiegelt sich wiederum in der Alltagssprache. Wenn eine Show nicht das beabsichtigte Publikum anzieht, sagt man schnell, „die Kommunikation ist gescheitert“. Wenn Werbung den Adressatenkreis nicht erreicht und das Produkt sich nicht verkauft, sagt man, "die Werbebotschaft ist nicht durchgedrungen“. Die Übernahme dieses engen Begriffs von Kommunikation als Kontrolle führt letztlich dazu, unbeabsichtigte Folgen von Kommunikation zu übergehen. Die nicht erfolgreiche Werbekampagne, die zu einer Welle von Witzen oder Gesprächen führte oder die Werbeagentur eines Besseren belehrte, hat immerhin wesentliche Konsequenzen. Selbst ein Wahlspot mit rassistischem Gehalt kann einem Kandidaten zwar ins Amt geholfen, aber gleichzeitig politische Werbung derart in Mißkredit gebracht haben, daß man künftig besser zweimal überlegen wird, die gleichen Mittel wieder zu 
verwenden. Kontroll-Metaphern begrenzen ihren Bereich möglicher Anwendungen auf instrumentell erfolgreiche Kommunikationen und verhindern dabei, daß Wirkungen, die außerhalb der beabsichtigten Ziele liegen, in das ihnen unterliegende Kommunikationskonzept eingehen.

Die Auffassung von Kommunikation als Mittel zum Zweck ist nicht auf den institutionellen Bereich begrenzt. Wenn jemand ein Gespräch damit beendet, daß er sagt: „Mir scheint, ich rede nicht mit Ihnen“", so kann sich diese Äußerung kaum auf das gegenseitige Verstehen dieser Äußerung beziehen, sonst wäre sie nicht gemacht worden, sondern darauf, daß der Sprecher nicht erreicht hat, was er wollte, nämlich die von ihm beabsichtigten Wirkungen. "Ich dringe zu Ihnen einfach nicht durch" (man beachte die Kanal-Metapher), "Sie hören ja nicht zu“ (man beachte, wie die Freiheit, jemandem nicht zustimmen zu müssen, hierbei umgewendet wird in eine soziale Beurteilung der Rolle eines Zuhörers, der aufmerksam und empfänglich für das Gesagte zu sein hat), ,Sie verstehen nicht“ (Verstehen wird hier vom Sprecher entschieden und nicht vom Hörer. Dessen Antworten werden als abweichend oder gar als fehlerhaft abgetan.)

Alle diese eher geläufigen Beispiele legen es nahe, von drei konzeptuellen Komponenten der Kontroll-Metapher auszugehen:

- Die Existenz von Kommunikation ist an ihrem Erfolg erkennbar. Kommunikation ist erfolgreich, wenn jemand dazu gebracht werden kann, zu glauben oder zu tun, was der Sprecher möchte.

- Kommunikation ist asymmetrisch. Sie verläuft vom Sprecher zum Hörer; Rückkopplung kann zwar vorhanden sein, ist aber den Zielen des Sprechers untergeordnet.

- Der Sprecher bestimmt die Kriterien dafür, ob etwas als Kommunikation gilt oder nicht. Er entscheidet darüber, ob der Adressat die ihm zugeschriebene soziale Rolle erfüllt und die beabsichtigten Wirkungen zeigt.

Eine Anmerkung zum Thema „Rückkopplung“ wird hier nötig. Monumente, so ließe sich heute behaupten, waren ebenfalls ein Mittel der Kontrolle, obwohl wir keinerlei Indiz dafür haben, daß sie damals als solche verstanden wurden. Wichtiger ist, daß Monumente keine Rückkopplung bedingen. Eine Möglichkeit, von den Zielgruppen Rückmeldungen über Wirkungen von Monumenten zu erhalten und diese dementsprechend abzuändern, gab es nicht. Veränderbarkeit aber wird gerade von der Kontroll-Metapher betont. Die Erkenntnistheorie des Konstruktivismus besteht zu Recht auf der Zirkularität von Kommunikation, die jedem Teilnehmer ein gleiches Veto-Recht zubiligt. Definiert man aber Kommunikation als Mittel zur Erreichung bestimmter Ziele gegen die Interessen anderer und rechtfertigt man diese Konzeption durch die Forderung nach Vereinbarkeit mit der Kontroll-Metapher, so wird zwar Rückkopplung nötig, aber nur im Sinne einer Bestätigungsfunktion. Die grundsätzliche Asymmetrie zwischen den Kommunikationspartnern bleibt bestehen.

Worin besteht der Kontroll-Metapher zufolge das Wesen der Kommunikation? Weshalb konnte diese Vorstellung sich in der Kommunikationsforschung etablieren? 


\subsection{Sind wir Opfer unserer Metaphern?}

Bewertung Die immensen Kapazitäten moderner Computer zur Informationsverarbeitung, die sich entfaltende Vielzahl verfügbarer Sprachen zur Erzeugung, Beschreibung, Berechnung und Übersetzung von Mustern; die wachsenden Möglichkeiten, mit anderen über große Entfernungen hinweg über Netzwerke verkehren und umfangreiche Datenbestände nahezu unmittelbar nutzen zu können; der Reichtum und die fast universelle Verfügbarkeit populärer massenmedialer Systeme haben uns eine Vielfalt der Auswahl beschert, die wohl jenseits individuellen Verstehens liegt. Frühere Technologien entwickelten sich noch langsam und brauchten ihre Zeit bei der Entwicklung von Modellen und Metaphern für das Verständnis von Kommunikation. Damit verglichen erweist sich die anhaltende technologische Entwicklung heute nicht nur als geradezu explosiv, sondern auch als fähig, die meisten der älteren Metaphern aufzunehmen und genügend Raum für neue zu lassen, die in die Auseinandersetzung über eben diese Kommunikationstechniken einfließen und sie damit tragen können. Dies ist zweifellos eine qualitativ neue Phase zwischenmenschlicher Beziehungen.

Der Benutzer eines Macintosh Computers etwa hat den Eindruck, er öffne Dateien, wandere durch Dokumente, reorganisiere, redigiere, schreibe Textdateien und werfe unerwünschte Textteile in einen elektronischen Papierkorb. Der Computer arbeitet jedoch nach einer Logik, die nur wenig mit solchen Benutzervorstellungen gemein hat. Im Computer gibt es keine Dateien, keine Papierkörbe, keine Zeichen des Alphabets, nicht einmal physikalische Objekte, die bewegt würden - es gibt nur komplexe Felder binärer Zustände, die sich angesichts anderer binärer Zustände ändern. Der Erfolg des Macintosh Computers liegt zum einen darin begründet, daß er von seinem Benutzer nicht einmal ein entferntes Verständnis davon verlangt, was in ihm vorgeht; und zum anderen darin, daß er Schnittstellen bietet, die an die vertraute Welt des Benutzers sinnvoll anschließen.

Der für das technische Kommunikationssystem Verantwortliche mag folgende Vorstellung vom Senden eines Telegramms oder einer Fax-Nachricht haben: Das originale Schriftstück wird elektronisch abgetastet, zerlegt, codiert, in ein kontinuierliches Medium zusammen mit anderen Signalen verschiedener Herkunft (und für viele andere Adressaten bestimmt) eingespeist. Diese Signale durchlaufen ein Netzwerk von Verbindungen, das sich ständig zugunsten seiner optimalen Effizienz organisiert (ohne daß jemand wissen könnte, wo und was die „Nachricht“ ist); sie werden an einen Satelliten abgestrahlt, transformiert, zurückgestrahlt, entschlüsselt ... und schließlich vom Empfänger reproduziert. Der Benutzer dieses Systems braucht von alldem nichts zu wissen. Er kann sich den Glauben leisten, daß das ursprüngliche Schriftstück in irgendeiner Form durch eine Leitung zum anderen Ende getragen wird, also eine Container-Metapher benutzen, solange deren Implikate nicht eigenen Erfahrungen widersprechen. Wenn der Benutzer nicht gerade mit dem technisch Verantwortlichen über das System sprechen muB, bleiben sich beide der wesentlich unterschiedlichen Modelle und Metaphern des anderen unbewußt, ohne das Funktionieren des Systems zu gefährden.

Diese beiden Beispiele für elektronische Kommunikation zwischen einem Computer (einer struktur-determinierten Maschine) und seinem wesentlich anders gearteten menschlichen Benutzer sowie zwischen zwei kognitiv kompetenten Freunden an entfernten Orten bedrohen keineswegs die Vorstellung der Beteiligten, in einer Papierwelt zu leben. Das Modell der Übertragung schriftlicher Botschaften behindert nicht ihre Kommunikation miteinander; es könnte diesen Prozeß im Gegenteil sogar befördern, insofern als es jedem seine eigenen Vorstellungen läßt. Die neuen elektronischen Medien der Kommunikation sind mit 
älteren Modellen und Metaphern durchaus beschreibbar. Diese älteren Konzepte eröffnen Möglichkeiten für die Entstehung oft höchst seltsamer Vorstellungen. Die Grenzen kommunikativer Entwicklung scheinen daher nicht länger technologischer Natur zu sein, zumindest heute weniger als früher. Sie liegen heute im Sprachgebrauch, in den Metaphern, die von Individuen, sozialen Gemeinschaften und Institutionen erfunden werden und die neue Medien trag- und lebensfähig machen können.

Modelle, Metaphern, aber eben auch Mythen der Kommunikation überleben kommunikative Praktiken, solange sie in der Praxis funktionieren. Zugleich bringen sie aber auch bedenkliche Implikationen mit sich. Daher ist es wichtig zu sehen, was diese Modelle und Metaphern bedeuten für die soziale Konstruktion zwischenmenschlicher Beziehungen, für die institutionellen Entwicklungen, die sie selektiv fördern, für die Technologien, deren Entwicklung sie dirigieren können, und nicht zuletzt für die Gesellschaftstheorien, in die sie einfließen. Für diese Implikationen zunächst zwei Beispiele, bevor wir einige Folgerungen für eine konstruktivistische Auffassung kommunikativer Phänomene und ihre Erforschung diskutieren.

Beginnen wir mit der unscheinbar anmutenden Metapher von Kommunikation als Mitteilung von Gemeinsamkeiten, die erstaunlicherweise einem Wolf im Schafspelz gleichkommt. Als Fundament von Freundschaft, Gemeinschaft und sozialer Organisation hoch geschätzt, nährt und begünstigt diese Metapher jedoch ihr Gegenteil: eine Autorität repressiven Charakters. Wenn man - wie bereits dargestellt - Botschaften als Behälter für Inhalte versteht, die objektiv existieren und damit Bestandteil einer beobachter-unabhängigen Wirklichkeit sind, dann müssen kommunizierte Inhalte identisch sein für denjenigen, der sie in den Container legt, und für den, der sie ihm entnimmt. Jeder, der dieselbe Nachricht erhält, müßte ihr folglich dasselbe entnehmen. Da Gemeinsamkeit eine gesellschaftlich hoch bewertete Norm ist, wird die Erfahrung von Uneinigkeit oder Diskrepanz zwischen Absicht und Aufnahme oder zwischen unterschiedlichen Interpretationen derselben Botschaft zwangsläufig zum Ärgernis. Wenn solche Diskrepanzen offensichtlich werden, wird die hier benutzte Metapher jedoch nicht gleich aufgegeben. Man ist eher geneigt, entweder den technischen Übertragungsprozeß für unzuverlässig oder, was sozial viel wichtiger ist, die Kommunikatoren für inkompetent, abweichlerisch oder im Irrtum befindlich zu halten.

Die Kommunikatoren für solche Diskrepanzen verantwortlich zu machen, erweckt drei typische Reaktionen, die allesamt inhuman sind:

- Man kann Wahrnehmungs-, Wissens- oder Interpretationsunterschiede entweder als Fehler, als pathologisch, als hinterhältige Verhaltensweise oder als bloße Belustigung erklären und als solche abweisen. Wir weisen sie als Fehler ab, wenn wir solche Diskrepanzen auf Unfähigkeiten, Zufälle oder unwillentliche Ereignisse zurückführen können. Wir lehnen sie als pathologisch ab, wenn wir sie mit Hilfe von krankhaften Umständen, wie etwa Schizophrenie, erklären können, die jemanden daran hindern, „normal“ $z u$ handeln. Wir lehnen sie als hinterhältige Verhaltensweise ab, wenn wir Gründe haben, versteckte Motive für ein Verhalten zu unterstellen, so etwa die kalkulierten Mehrdeutigkeiten in politischen Wahlkampagnen oder einfache Zwecklügen. Schließlich weisen wir sie als unterhaltsame Kuriositäten $a b$, wenn wir ihre Realität in Frage stellen können, so beispielsweise die Paradoxa, die Logiker zweitausend Jahre lang erfreut haben, bevor WhITEHEADS und RuSSELLS Theorie der logischen Typen ${ }^{7}$ sie als bedeutungslos erklärte und aus jedem rationalen Diskurs ausklammerte.

7 Alfred North WhitehEAd / Bertrand Russell: Principia Mathematica. Frankfurt 1986, S. 55 ff. (zuerst 1925). 
Alle diese Abweisungen setzen die Autorität eines so Urteilenden voraus. Jemand, der für sich beansprucht, ablehnen zu können, was andere einer Botschaft entnehmen, muß sich selbst als fehlerfrei sehen, sonst würde er die Fehler anderer nicht als solche erkennen können; er muß Zugang zu allgemeingültigen Normen haben, sonst könnte er Pathologien nicht diagnostizieren; er muß überlegene Kenntnisse über die wahren Motive anderer besitzen, sonst könnte er hinterhältige Verhaltensweisen nicht als solche entlarven; und vor allem muß er privilegierten Zugang zur objektiven Realitäł haben, sonst könnte er Magisches und Paradoxa (und vielleicht auch Metaphern) nicht als unreal aus der Wissenschaft, der Objektivität und der Realität ausklammern. Es ist fast überflüssig hinzuzufügen, daß denjenigen, deren Wahrnehmung, Interpretation oder Meinung als abweichend abgewiesen wird, damit auch ihre kognitive Autonomie abgesprochen wird. Sie müssen sich der von den Metaphern hervorgebrachten Autorität beugen.

- Diskrepanzen im Verständnis einer Botschaft, die nicht durch Abweisung aus der Welt geschafft werden können, können der Vermittlung durch eine andere Autorität unterworfen werden. Diese Autorität kann eine besonders angesehene Persönlichkeit, ein institutionalisiertes Verfahren oder beides sein. Wenn wir einen Redner fragen, was er meinte, dann geben wir diese Autorität dem Sprecher. Tatsächlich gibt es eine ganze rhetorische Tradition, welche die Intention eines Sprechers zum alleinigen Richter korrekter Interpretationen macht. Immerhin sind die Wörter "Autor" und "Autorität" gleichen Ursprungs. Wenn ein Autor nicht zwischen verschiedenen Lesarten seines Werkes vermitteln kann, dann gibt es andere Autoritäten, Experten, Richter oder entscheidende Persönlichkeiten, die entweder befragt werden können oder die von sich aus ein Interesse daran haben, ihre Legitimität in solchen Situationen zu beweisen. Professoren machen vom Privileg ihrer institutionellen Autorität Gebrauch, indem sie die Arbeiten ihrer Studenten hinsichtlich der Frage bewerten, was wichtig ist und wie Wirklichkeit gesehen werden muß. Orthodoxe wissenschaftliche Verfahren verleihen Daten und Fakten institutionelle Autorität, die Nichtwissenschaftler nicht zu bezweifeln wagen aus Angst, sich öffentlich lächerlich zu machen. Die letztlich bedeutendste institutionelle Autorität ist das Rechtssystem. Schon von seiner Konstitution her kann ein Gericht immer nur eine von mehreren Interpretationen einer Rechtslage zulassen. Es muß bestimmen, was die Fakten sind und welches Urteil als gerecht anderen Gerichten gegenüber angesehen werden kann.

- Diskrepanzen, die weder einfach abgewiesen noch durch Vermittlung entschieden werden können, vermögen physische Gewalt hervorzurufen. Physische Gewalt wird nicht nur von Kriminellen und zu persönlicher Bereicherung ausgeübt, wie uns das Fernsehen glauben machen möchte, sondern wesentlich häufiger zu Hause, in der Familie und wo auch immer mit diesen Metaphern kommuniziert wird. Gewalt in den Familien geht selten um das tägliche Brot, Liebe oder Kinder, sondern darum, wer recht, wer also die Autorität hat, darüber zu entscheiden, wessen Interpretation als wahr zu akzeptieren ist. Auch internationale Konflikte sind unzweifelhaft in Sprachgebrauch eingebettet, wobei im Konfliktfall die eine Seite gewöhnlich glaubt, ihr Anspruch sei korrekt, vernünftig und historisch gerechtfertigt, und der anderen Seite vorwirft, sie sei nicht willens, diese eine Interpretation zu akzeptieren. Wir wollen hier nicht den Eindruck erwecken, als sei alle Gewalt ausschließlich auf Sprache zurückzuführen. Doch rührt Gewalt meistens daher, daß die Metapher des Mitteilens, die Vorstellung, Kommunikation müsse Gemeinsamkeiten zur Folge haben, dort angewandt wird, wo sie einfach nicht paßt und ihre Implikate dann nicht mehr im Gespräch der Beteiligten reflektiert werden können.

Sozialwissenschaftler der sog. kritischen Schulen diskutieren Gewalt häufig unter dem Gesichtspunkt von Macht und Ideologie. Der Gebrauch dieser physikalischen Metapher ist jedoch weder hilfreich noch brauchbar, insbesondere wenn wir schon 
mit der Anwendung der Metapher, wonach Kommunikation zu Gemeinsamkeiten führen muß, genügend Macht etablieren, die keinen Respekt vor der kognitiven Autonomie einzelner Menschen zuläßt. Physikalische Metaphern enthalten einen Determinismus, dem zufolge der Mensch nicht frei handeln und daher auch keine Verantwortung übernehmen kann. ${ }^{8}$

Der Bedarf an Autorität läßt sich auch am Gebrauch der Kanal-Metapher ablesen.

Die Ähnlichkeit dieser beiden Metaphern liegt in der in beiden vorausgesetzten Objektivität, die hier den von einem Ort zum anderen fließenden Zeichen, Symbolen oder Informationen zugeschrieben wird. Ausdrucksweisen wie „Ich gebe dir ein Zeichen" (wobei ein Zeichen hier ein physikalisches Ereignis ist), „Dieses Symbol bedeutet etwas ganz Bestimmtes“, „Dieser Index gibt über jenen Sachverhalt Aufschluß" machen deutlich, daß Zeichen als handelnde Instanz (Agens) wirken, ganz gleich ob sie von jemandem als solche erkannt werden oder ob jemand sie so zu sehen wünscht. Nicht anders verhält es sich mit der semiotischen Zeichentheorie, die auf der Unterscheidung zwischen Zeichenträger und Zeichen beruht, das erstere als Mittel für das letztere sieht, um damit ein Bezugsobjekt der wirklichen Welt zu ersetzen oder darauf zeigen zu können. $\mathrm{Ob}$ man nun, wie es in der Semiotik üblich ist, unterscheidet zwischen einem Index, dessen Referenten von Natur aus zugeordnet sind, und einem Symbol, dessen Referenten durch Konvention festgelegt sind, ist zweitrangig. Fragen wie „Was bedeutet dieses Zeichen?" können letztlich nur von einer Autorität für diejenige Wirklichkeit beantwortet werden, aus der das Zeichen stammt. Vergleichsweise würden Fragen wie „Wie willst du dieses Zeichen (in deiner Welt) benutzen?" nicht nach einer Autorität außerhalb des Benutzers suchen; sie geraten aber mit der Vorstellung in Konflikt, daß Zeichen objektiv existieren und als solche, das heißt als Zeichenträger und Getragenes, fließen können.

Anders als die Metapher der Mitteilung von Gemeinsamkeiten, die Symmetrie in den gesellschaftlichen Beziehungen ausdrückt und gleichzeitig Autoritäten hervorbringt, welche die erforderliche Gemeinsamkeit zu erzwingen suchen, verankert die Kontroll-Metapher Asymmetrie direkt im Prozeß der Kommunikation. Diese Metapher meint zwei getrennte Welten: die Welt der zu kontrollierenden Rezipienten, Zuhörerschaften oder Zielgruppen und die Welt der kontrollierenden Urheber von Kommunikationsprozessen, der Kommunikatoren.

Die Kontroll-Metapher entzieht den Rezipienten die ihnen eigene Macht. Überzeugende Redner, starke Anreize und zwingende Argumente brechen den Widerstand eines Publikums, nicht weil sie mächtig wären, sondern weil die Rezipienten sie so konstruieren. Die Ohnmacht der Rezipienten drückt sich auch in der vertrauten Subjekt-Objekt-Gliederung indoeuropäischer Sprachen aus, in denen wir unter anderem das „Wer-sagt-was-wem“ der Kommunikation beschreiben. Diese Satzform weist Objekten die passive Rolle zu und macht aus Subjekten willentlich Handelnde, also Kontrolleure. Als Mittel in einer von Kontrolleuren ausgehenden instrumentellen Kette von Ereignissen werden Zuhörerschaften idealerweise vorhersagbar, passiv in den Reaktionen und unpersönlich oder anonym. Da das Bewußtsein und der Wille der Rezipienten leicht die Vorhersagbarkeit ihres Verhaltens durchkreuzen können, bilden unbewußte Prozesse, unterschwellige Einflüsse und unreflektierte Reaktionen den bevorzugten Hintergrund, auf dem Publikumsreaktionen erklärt und erfolgreiche Kommunikationskampagnen entworfen werden.

Im Gegensatz dazu läßt die Kontroll-Metapher die Welt der Kontrolleure wesentlich anders erscheinen. Willentlich Handelnde, häufig einfach „Kommuni-

8 Klaus KrtppendorfF: The power of communication and the communication of power. Towards an emanzipatory theory of communication. Communications, 1990 (im Druck). 
katoren" genannt (denn ein passiv reagierendes Publikum spielt dann nur die untergeordnete Rolle), entscheiden rational über die Gestaltung von Botschaften, sind in der Lage, komplexe Voraussetzungen und verfügbare Informationen über erwartbare Publikumsreaktionen in Erwägung zu ziehen, und benutzen ihre Kreativität, Intelligenz und Autorität, selbstgesetzte Ziele zu erreichen. Die Gleichsetzung von Kommunikation mit Kontrolle bedeutet das Privileg der Kommunikatoren, Ziele zu verfolgen - ein Bestreben, das den Adressaten versagt bleibt oder bestenfalls als zu überwindende Störung bezeichnet wird. Sie verleiht Macht denen, die über Kommunikationsprozesse als Mittel gebieten, und Ohnmacht und Unwissen denen, die sich diesen Mitteln aussetzen müssen.

Wer sich der Kontroll-Metapher bedient, gleich auf welcher Seite er steht, muß Kommunikation grundsätzlich als interessen- und intentionsbedingt sehen. Kommunikationsinhalte können dann auch nicht länger für bare Münze genommen werden. Sie sind potentiell irreführend. Rezipienten, die sich der Kontrolle bewußt sind, werden gezwungen, zwischen den Zeilen zu lesen, unausgesprochene Motivationen zu suchen und auf die unterstellten Interessen der Kommunikatoren zu reagieren. Der Verdacht, von Argumenten überrollt zu werden, weckt jene Angst, welche die auf Manipulation ausgerichteten Kommunikatoren durch zunehmend geschickteres Manövrieren vermeiden müssen, was letztlich in einer Spirale von Mißtrauen endet. Die Kontroll-Metapher zerstört daher symmetrische zwischenmenschliche Beziehungen. So werden etwa intime Beziehungen sofort zunichte gemacht, wenn der eine Partner herausfindet, daß der andere ihn nur als Mittel zum Zweck gebraucht. Liebe ist mit instrumentellem Handeln unvereinbar, und der Dialog, durch den zwei oder mehrere Teilnehmer ihr jeweiliges Verständnis einer Sache im Gespräch miteinander verbessern könnten, wird durch den Gebrauch von Kontroll-Metaphern effektiv verhindert.

Aufgabe $6 \quad$ Welche Strategien werden alltäglich benutzt, um Diskrepanzen zwischen den Absichten eines Kommunikators und dem Handeln eines Rezipienten zu erklären oder zu beseitigen?

6.10. Eine konstruktivistische Auffassung von Kommunikation und ihrer Erforschung

Folgerungen Was können wir nun aus diesen Modellen und Metaphern der Kommunikation lernen? Eine traditionelle Antwort fiele wohl in Form einer Verallgemeinerung aus, welche die alltagssprachlichen Redeweisen als Beschreibungsvarianten einer allen zugrundeliegenden Erscheinung ansieht und Gemeinsamkeiten als deren gesuchte Verallgemeinerung nähme. Dies ist ein eher hoffnungsloses Unterfangen. Modelle, Metaphern und andere Bestimmungsformen von Kommunikation sind so sehr an ihren konkreten Gebrauch wie an die Geschichte der Kommunikationstechnologie gebunden, daß eine Abstraktion von allen jenen Bedingungen, die den Kommunikationsprozessen ihre soziale Bedeutung geben, nur wenige erwähnenswerte Gemeinsamkeiten zutage fördern könnte.

Eine andere traditionelle Antwort bestünde wohl darin, die volkstümlichen Modelle und alltagssprachlichen Metaphern als naive Beschreibungen einer 
unwissenden Öffentlichkeit zurückzuweisen und sie als Mythen aufzufassen, die nur der qualifizierte Wissenschaftler objektiv klären kann. Objektivität verlangt nüchterne oder operationale Erklärungen einer Wirklichkeit, die als außerhalb und beobachterunabhängig existent angenommen wird. Anhängern dieser Auffassung von Wissenschaft fällt es schwer, sprachlich kompetente Subjekte in ihren Theoriebildungen zu berücksichtigen. Daher bevorzugen sie naturwissenschaftlich orientierte Ansätze, vor allem physikalisch meßbare Sachverhalte, und sehen von der eigenen Institution her nicht, wie sehr ihre Erklärungen dem Reichtum alitagssprachlicher Redeweisen (die hier besprochenen Modelle und Metaphern der Kommunikation eingeschlossen) entwachsen. Naturwissenschaftlich orientierte Kommunikationstheorien haben es möglich gemacht, mit Raumsonden in der Nähe des Neptuns zu kommunizieren und die breite technologische Infrastruktur moderner Kommunikation voranzutreiben. Dennoch sind es die „volkstümlichen Theorien von Kommunikation", die Modelle, Metaphern und Mythen, welche die kommunikative Praxis der Menschen und ihren Gebrauch von Kommunikationstechnologien leiten.

Davon ausgehend soll im folgenden versucht werden, einen konstruktivistischen Ansatz für das Verständnis menschlicher Kommunikation zu entwickeln, das heißt nicht eine neue allgemeine Theorie, sondern einen erkenntnistheoretischen Rahmen für das Verständnis der Rollen, die Modelle und Metaphern in der Kommunikationspraxis spielen. Erkenntnistheorie ist eine philosophische Disziplin, die sich damit beschäftigt, wie wir zu Wissen gelangen (nicht was wir wissen). Der nachfolgende Rahmen soll nicht allein auf die bereits diskutierten Modelle und Metaphern anwendbar sein, sondern auch auf Alltagstheorien, die das Selbstverständnis von Teilnehmern an Massenkommunikation prägen, wie auch auf solche wissenschaftliche Theorien, die auf Grund der wissenschaftlichen Autorität ihrer Begründer bestimmte kommunikative Praktiken beeinflussen. Dieser Ansatz wird hier in Form von 6 Thesen zum Gebrauch von Modellen und Metaphern der Kommunikation skizziert:

(1) Es gibt offensichtlich nicht nur ein einziges allgemeines Kommunikationsphänomen, das ein Modell beschreiben und eine Metapher erhellen könnte.

- Die angeführten Modelle und Metaphern sind im Kontext unterschiedlicher Praktiken entstanden: dem Überbringen einer von übernatürlichen Mächten empfangenen Inspiration an das gemeine Volk, dem Tragen schriftlicher Botschaften von einem Ort zu einem anderen, der Argumentation als einer Art von Kriegsführung, der Kontrolle menschlichen Verhaltens aus der Distanz. Die Phänomene, die zu diesen Modellen und Metaphern führten, existieren nicht unabhängig von eben diesen Modellen und Metaphern, werden durch sie erst zur als solche erfahrbaren Wirklichkeit, können im Einzelfall heute bereits nicht wieder hervorgerufen werden und sind letztlich von geringer Bedeutung. Wie Menschen ihre Praxis konzeptualisieren, was ihnen bewußt ist und was sie berücksichtigen, wenn sie bestimmte Handlungen vollziehen, zeigt sich dagegen im physischen und sprachlichen Gebrauch dieser Darstellungen.

- Die Modelle und Metaphern haben ihre Geschichten, und man kann sicher davon ausgehen, daß in ihnen nicht nur eine Geschichte der Kommunikationsmedien und Technologien eingeschlossen ist, sondern auch die Geschichte des gleichzeitigen Sprachgebrauchs, des geselischaftlichen Bewußtseins und der Kognition. Das Meißeln in Stein, das Schreiben auf Papyrus und Papier, das Druckwesen, das Telefon, Radio, Fernsehen und die Computertechnologie hätten sich ohne Sprache und Kommunikation nicht in der Weise, wie es geschehen ist, ausbreiten können. Und die verwendeten Modelle und Metaphern wurden ebenso von der Entwicklung der technologischen Möglichkeiten der Kommunikation geleitet, wie sie umgekehrt diesen Fortschritt selbst auch vorangetrieben haben. 
- Die Vielzahl gleichzeitig verfügbarer Modelle und Metaphern der Kommunikation bietet nicht nur Alternativen. Sie konstituiert auch eine komplexe Ökologie sich wechselwirkend beeinflussender "Arten", die miteinander kooperieren und konkurrieren, neue metaphorische Bündnisse eingehen, sich selbst in Absurditäten verlaufen, sich in Nischen begeben oder einander ersetzen können - so etwa als die Container-Metapher mit der Kanal-Metapher verbunden und gar zum Kernstück ingenieurwissenschaftlicher Darstellung von Kommunikation wurde. Einige Modelle und Metaphern erweisen sich als überlebensfähiger in dieser Ökologie als andere. Was jedoch ihre Wechselwirkungen ermöglicht, was ihre Geschichte erschafft, was zu ihrer Entwicklung führt, was sie in die Praxis umsetzt, was diese komplexe Ökologie ins Leben ruft und nährt, ist der menschliche Geist, sind Kognition und Kommunikation.

(2) Was wir auch immer sagen, tun und sogar sind - wir können immer nur in der Wirklichkeit handeln, die wir verstehen und die uns unsere eigene Wahrnehmung sinnvoll macht. Wenngleich daraus folgen würde, daß ich nur mit mir selbst sprechen könnte - durch den Gebrauch von ,wir“ möchte ich diese These auch für andere mir ähnliche Personen gültig sehen, also meine Prinzipien der Konstruktion von Wirklichkeit auf andere verallgemeinern. Und diese These lautet, daß jeder von uns immer so handelt, daß uns dieses Handeln sinnvoll erscheint, jedem und jeder für sich selbst, in der doppelten Bedeutung von "Sinn" als den Sinnen zugänglich und als bedeutungsvoll, verstehbar und verständlich. Die zentrale Einsicht in William Powers' Arbeit ist, daß Handlung und Wahrnehmung eine zirkuläre, kausale, eine Umgebung durchlaufende Rückkopplungsschleife bilden, durch die wir weder unsere eigenen Wirkungen auf die Außenwelt noch die Objekte in unserer Umgebung objektiv kontrollieren, sondern ausschließlich unsere Wahrnehmung von Ereignissen und Gegenständen. ${ }^{9}$ Aus der Perspektive eines objektiven, von außen sein Objekt angehenden Beobachters, beispielsweise eines Gottes, der eine andere Realität sehen muß als wir, sagen, tun und sind wir wahrscheinlich wesentlich mehr, als wir an uns selbst oder in den Konsequenzen für unsere Umgebung beobachten können, etwa wenn wir andere unabsichtlich verletzen (Sadisten etwa sind sich selten bewußt, daß sie Sadisten sind) oder das ökologische System zerstören, das uns als menschliche Wesen geschaffen hat und belebt (vor hundert Jahren hatten wir noch keine Vorstellung von dem Verhältnis zwischen Technologie und Natur, der Notwendigkeit unserer Koexistenz mit anderen Lebensformen). Da wir konstitutionell nicht in der Lage sind, die Verbindungen zwischen unseren eigenen Handlungen und deren objektiven Wirkungen auf andere wahrzunehmen, können wir auch nicht auf diese Wirkungen handeInd Einfluß nehmen. Die Erfindung von Mustern, die sich miteinander verbinden lassen, das Erklären und Handeln gemäß parallelen Erfahrungen und Sinn aus anscheinend disparaten Beobachtungen zu machen, sind allesamt Akte der Konstruktion unserer eigenen kohärenten Wirklichkeiten, und zwar derselben, die wir letztlich sehen.

Wenn wir uns nun sprechen hören, macht unser Sprechen erst einmal für uns selbst Sinn, weil wir es so konstruiert haben. Hören wir dagegen das Sprechen eines anderen, so sind wir grundsätzlich nicht in der Lage, den Sinn herauszufinden, den es für den Sprecher macht. Wir können aber versuchen, für uns daraus Sinn zu machen, indem wir so tun, als wären es unsere eigenen Worte oder als hörten wir uns selbst sprechen. Auch wenn wir uns darum bemühen, unsere Interaktion mit anderen zu erklären, so sind es immer nur wir selbst, die den anderen als jemanden seben, der auf das, was wir gesagt haben, reagiert, oder uns als diejenigen sehen, die auf das, was andere gesagt haben, reagieren. Anders gesagt: Der Sinn, den uns

9 William T. Powers: Behaviour. The Control of Perception. Chicago 1973, bes. Kap. 4 „Feedback and Behaviour“, S. 41-56. 
unsere Kommunikation mit anderen macht, ist stets unser eigener, obwohl durch die Konstruktion eines anderen reflektiert. Eine Möglichkeit, unser Verständnis von etwas mit dem eines anderen objektiv zu vergleichen, gibt es nicht. Verstehen ist immer persönlich und privat. Wir haben keine Möglichkeit, die Gleichheit oder Ähnlichkeit individuellen Wissens und Denkens direkt erfahren zu können.

Daraus folgt, daß auch die Kommunikationen, an denen wir uns bewußt beteiligen, die wir mit unseren eigenen Augen sehen, unsere eigenen Konstruktionen sind und nicht ohne unsere aktive Teilnahme an diesem Prozeß existieren können. Sie sind ein wichtiger Bestandteil der von uns konstruierten oder erfundenen Wirklichkeiten, können nicht ohne unsere Körper stattfinden, sind subjektabhängig (was nicht mit subjektiv zu verwechseln ist) und verlangen von uns, eine Position innerhalb unserer eigenen Konstruktionen einzunehmen.

(3) Lebensfähige Wirklichkeitskonstruktionen sind operational geschlossen und können nicht außerhalb eines Mediums existieren. Um ein abstraktes Beispiel zu geben: Wenn A B bewirkt, B C bewirkt, und C A bewirkt, dann bewirkt jedes sich selbst mit Hilfe eines anderen, ist selbstreferentiell, hat sein „eigenes Leben“ als Ganzes und widersetzt sich weitgehend äußeren Einflüssen. Da die Konsequenzen seines Operierens nun Teil seiner Operanden sind, das System sich also selbst beeinflußt, sagt man, das System sei operational geschlossen. Operational geschlossene Systeme können nur in einer Umgebung existieren (entstehen oder erfahren werden), die, ohne das Operieren des Systems zu unterbrechen, die nötige Energie zur Erhaltung der Zirkularität des Prozesses und eventuell auch die Materie zur Ersetzung ausgefallener Komponenten liefert. Solche Systeme müssen daher offen gegenüber Materie und Energie sein. Operational geschlossene Systeme können auch durch Einflüsse außerhalb des Systems gestört werden, also das Verhalten der Komponenten des Systems verändern, nicht aber innerhalb des Systems als das, was sie ,tatsächlich“ sind, erkannt werden. Informationstheoretiker würden solche Störungen als Rauschen auffassen, Physiker als Chaos. Ein System, das seine operationale Geschlossenheit angesichts von Störungen bewahrt, beweist seine Lebensfähigkeit. Ein System, das unter solchen Störungen zusammenbricht, ist entsprechend nicht länger lebensfähig.

Im Bereich der menschlichen Kognition findet Wirklichkeitskonstruktion weder in den Köpfen von Individuen statt, wie Solipsisten es annehmen, noch läßt sie sich außerhalb des menschlichen Körpers entdecken, worauf Objektivisten pochen. Kognition liegt in den operational geschlossenen Praktiken lebender Systeme einschließlich ihrer Umwelt. Augen können nicht sehen, sondern ermöglichen, daß Störungen in jene zirkuläre Organisation der Kognition eingehen können, deren Teil sie sind. Wir können nicht sehen, was wir sehen, wir können uns nur des Sehens bewußt werden.

Mit jemandem irgendeinem Kommunikationsmodell gemäß zu kommunizieren, ist wie das Fahren nach einer Straßenkarte durch ein anderweitig nicht erkennbares Terrain. Die Wirklichkeitskonstruktionen, die eine Karte bietet, entfalten sich erst in der Praxis des Fahrens. Ein Modell begrenzt also die Menge der denkbaren Möglichkeiten, ist aber ohne praktischen Wert wie ein unbenutzter Straßenatlas im Bücherregal, solange seine Angebote nicht praktisch umgesetzt werden. Unsere Wirklichkeitskonstruktionen einschließlich der Kommunikationsmodelle werden lebensfähig, solange wir keine Unstimmigkeiten (zwischen dem, was wir sehen sollten, und dem, was wir sehen) erleben. So ist es möglich, mit dem Computer zu kommunizieren, als ob wir Dokumente manipulierten. So ist es möglich, anzunehmen, wir würden miteinander kommunizieren, indem wir Botschaften hin und her schicken, obwohl wir eigentlich nichts anderes tun als Sprechen - solange unsere Vorstellung, Botschaften zu versenden und ihnen Inhalte zu entnehmen, nicht zu Widersprüchen führt. Sobald die sich in der Praxis entfaltenden Wirklichkeits- 
konstruktionen zu Widersprüchen oder gar einem Zusammenbruch führen, verlieren sie ihre Lebensfähigkeit, etwa wenn Botschaften als Container von Einheiten verstanden werden und man erlebt, daß zwei Leser einer Zeitung ihr höchst unterschiedliche Inhalte entnehmen; oder wenn man Kommunikation als Kontrolle auffaßt und im Rahmen eines Liebesverhältnisses zu realisieren sucht, das dann folglich zusammenbricht. Natürlich gibt es eine Vielzahl kognitiver Strategien, mit denen man Wirklichkeitskonstruktionen, die sich in bestimmten Situationen als nicht lebensfähig erwiesen haben, zu retten sucht: etwa indem man sie weiteren Prüfungen entzieht; indem man bestimmten Implikaten nicht weiter nachgeht; indem man ihren Gebrauch auf Situationen beschränkt, in denen sie funktioniert haben, usw.

(4) Kommunikation erfordert die Konstruktion anderer Kommunikationspartner, ergänzend zur Konstruktion des Selbst. Wenn zwei Individuen sich bewußt werden, miteinander kommunizieren zu können, so können sie sich weder als Solipsisten verstehen, indem sie glauben, sie seien der Mittelpunkt ihres eigenen Universums und jedem anderen überlegen, noch als Objektivisten, indem sie einander als strukturdeterminierte Maschinen sehen, die möglicherweise unterschiedlich, aber auf objektiv identifizierbare und folglich beobachterunabhängig existierende Ereignisse, Gegenstände, Zeichen, Symbole, Bilder usw. reagieren. Im ersten Fall würde das verletzt, was Heinz voN FoERSTER das Prinzip der Relativität genannt hat. Es besagt, daß jede Hypothese zurückzuweisen ist, die für jedes einzelne zweier getrennter Ereignisse, aber nicht für beide zusammen gilt. ${ }^{10}$ Demnach können zwei Solipsisten nicht co-existieren, geschweige denn miteinander kommunizieren, denn keiner kann gleichzeitig eine Position im Mittelpunkt einer gemeinsamen Welt einnehmen. Der zweite Fall läuft letztlich auf einen Widerspruch hinaus: Man kann nicht annehmen, mit jemandem kommunizieren zu können, also aus seinen Vorstellungsmöglichkeiten, Modellen, Metaphern wählen zu können, und zugleich behaupten, man verhalte sich wie eine strukturdeterminierte Maschine, deren Implikate eine solche Wahlfreiheit ausschließen. Wenn jemand, der für sich kognitive Autonomie bei der Konstruktion seiner Wirklichkeiten in Anspruch nimmt, einen anderen konstruiert, der für sich dieselbe Autonomie in Anspruch nimmt, so kann ersterer nicht länger nur allein autonom sein. Für einen Konstruktivisten, der meint, Wirklichkeit finde weder innerhalb noch außerhalb eines lebenden Organismus statt, sondern in den operational geschlossenen sozialen Praktiken in einem Medium, impliziert zwischenmenschliche Kommunikation, einen Prozeß der Konstruktion anderer mit uns ähnlichen Fähigkeiten, ihre eigenen Wirklichkeiten zu konstruieren, die uns wiederum als kognitive autonome Wesen in ihre Konstruktion einschließen, usw. Sprachliche Modelle und Metaphern sind in einem solchen rekursiven Konstruktionsprozeß eingebettet, durch den wir mehr oder weniger in die Lage versetzt werden, uns selbst durch die Augen anderer zu sehen.

Für Konstruktivisten ist es eine ethische Frage, anderen Personen zumindest die gleichen kognitiven Fähigkeiten zuzuschreiben, die sie bei ihrer Konstruktion anderer in Anspruch nehmen. "Ein solcher ethischer Imperativ mag jedoch nicht immer für jedermann und für alle Situationen akzeptierbar sein. So wird im Verhältnis von Vorgesetzten zu Untergebenen (wie etwa beim Militär) von beiden Partnern erwartet, daß sie ihre jeweiligen Rollen erfüllen und sich auf die Kontroll-Metapher für die Organisation ihres kommunikativen Handelns einlassen. Um aber kommunizieren zu können, ist es grundsätzlich erforderlich, daß

10 Heinz VON FoERSTER: Sicht und Einsicht. Versuche zu einer operativen Erkenntnistheorie. Braunschweig/Wiesbaden 1985, S. $40 \mathrm{f}$.

11 Klaus Krippendorff: On the Ethics of Constructing Communication. In: Brenda Dervin u. a. (Hrsg.): Rethinking Communication (s. Anm. 3), S. 88f. 
jeder Partner Annahmen darüber bildet, wer der andere ist, wie er wiederum seinen Partner konstruiert, einschließlich nach welchen Kommunikationsmodellen er handelt - das heißt, sie müssen sich selbst und den anderen in Einklang mit der sprachlichen Praxis rekursiv konstruieren.

Geht man davon aus, daß Kommunikationspartner innerhalb ihrer eigenen Wirklichkeitskonstruktionen und im Verstehen eines anderen handeln, so müssen sich die Konstruktionen des Selbst und des anderen (operational) komplementär zueinander verhalten. Abgesehen von solchen komplementären Rollen wie Eltern und Kinder, Käufer und Verkäufer, Arzt und Patient, Polizist und Krimineller, Entertainer und Publikum usw. - keines dieser Komplemente kann übrigens ohne sein Gegenstück in einer Wirklichkeitskonstruktion vorkommen - beherrscht Komplementarität auch den Diskurs. Die Praxis eines erfolgreichen Kommunikationsmodells läßt deshalb zwar auf die Komplementarität der am Prozeß beteiligten Wirklichkeitskonstruktionen schließen, nicht aber auf deren Gleichartigkeit. Ernst VON GLASERSFELD sagt sicher dasselbe, wenn er behauptet, daß Konstruktionen zu ihrer Umgebung ,passen“ müssen, und das Beispiel eines Schlüssels aufgreift, der zwar viele Türen öffnen kann, aber nicht in jedes Schloß paßt. ${ }^{12}$ Mit einem Schlüssel in der Hand kann man über ein $S c h l o ß$ nicht mehr erfahren, als daß er schließt. Modelle und Metaphern, die sich in der Kommunikationspraxis bewähren, also lebensfähige rekursive Konstruktionen entfalten, erlauben uns ebenfalls nicht mehr zu sagen, als daß unsere Konstruktionen zu möglichen Konstruktionen anderer passen.

(5) Sprachgebrauch konstituiert soziale Wirklichkeiten. Von den Beschreibungsund Überzeugungsfunktionen, die der Sprache üblicherweise zugeschrieben werden, einmal abgesehen, wird die Rolle, welche die Sprache in der Gestaltung von sozialen Wirklichkeiten spielt, weitgehend ignoriert, obwohl sie für das Verständnis von Kommunikation wohl am wichtigsten ist. Mit dem Bezug auf „Soziale Wirklichkeit" ist nicht beabsichtigt, eine Unterscheidung zwischen Natur und gestalteter Welt bzw. Kultur hervorzurufen. Er soll vielmehr dafür Rechnung tragen, daß es höchst individuelle Erfahrungen gibt, die schwierig zu verbalisieren sind, oder daß man sich eigener kognitiver Konstruktionen bewußt sein kann, die sich ohne Bezug auf Sprache oder andere Menschen gebildet haben. Der größte Teil unseres Wissens wird jedoch in Kommunikation mit anderen und durch den Sprachgebrauch erworben und ist folglich sozialer Natur. Die Vorstellung, Sprache könne soziale Wirklichkeiten konstituieren, das heißt ein wesentlicher Bestandteil genau der Wirklichkeit sein, die sie definiert, geht auf Ludwig WiTTGENSTEIN zurück, der den Begriff von Sprache als Spiel, das von Sprechern gespielt wird, entwickelte und betonte, daß Wörter eben auch Handlungen seien. ${ }^{13}$ J.L. AustiN ${ }^{14}$ ergänzte diese Vorstellung um das Konzept der performativen Sprechakte, das heißt um Äußerungen, die genau das tun, was sie besagen, wie etwa Versprechen, Verpflichtungen, Deklarationen usw. Wenn beispielsweise ein Pfarrer unter geeigneten Voraussetzungen an zwei Personen gerichtet sagt: "Hiermit erkläre ich euch zu Mann und Frau“, dann macht diese (performative) Äußerung aus einem Mann einen Ehemann und aus einer Frau eine Ehefrau. Sie verpflichtet das Ehepaar, diese Bezeichnungen auch so miteinander zu benutzen und schafft damit eine komplementäre Beziehung zwischen den beiden und der größeren Gemeinschaft, die den Vollzug der Eheschließung (als konstitutive Handlung) darstelit. Performative Äußerungen tun, was sie sagen.

12 Enst von Glasersfezd: Einführung in den radikalen Konstruktivismus. In: Paul WATZLAWICK (Hrsg.): Die erfundene Wirklichkeit. Wie wissen wir, was wir zu wissen glauben? Beiträge zum Konstruktivismus. München/Zürich ¹985, S. 20 f.

13 Ludwig Wittgensteın: Philosophische Untersuchungen. In: Werkausgabe in 8 Bänden. Band 1. Frankfurt 1984, S. 225-580.

14 John Langshaw Austin: Zur Theorie der Sprechakte. Stuttgart 1972 (zuerst: 1962). 
Die Erfahrung von Komplementarität, die Erfahrung zu wissen, einschließlich der Annahme, das Wissen anderer zu kennen, die Erfahrung zu kommunizieren, kann nur aufrechterhalten werden, indem man sich am Diskurs beteiligt, indem man Sprachfiguren koordiniert gebraucht, wie etwa in einem Wittgensteinschen Sprachspiel. Zur Klärung der konstruktivistischen Grundlage sozialer Wirklichkeit hat John SHotTer die These entwickelt, nach der kompetente Sprecher einer Sprache soziale Rechenschaft für den Sprachgebrauch sowohl fordern als auch zu geben gewillt sind. ${ }^{15}$ Wenn wir miteinander sprechen, verwenden wir Modelle und Metaphern, die nicht nur für uns Sinn machen, sondern tun dies in der Erwartung, $\mathrm{da} ß$ sie anderen ebenso sinnvoll erscheinen. Wir sind uns der Möglichkeit bewußt und sprechen in dem Bewußtsein, daß wir von anderen beurteilt und verantwortlich gehalten werden für das, was wir sagen, wie wir es sagen, und für den Sinn, den das von uns Gesagte für andere macht. Die damit verknüpfte Erwartung, für das Gesagte verantwortlich gehalten zu werden und gegebenenfalls Rechenschaft dafür abgeben zu müssen, ist eine notwendige Folge unserer Konstruktion anderer als sprachlich kompetenter Kommunikationspartner. Im Rahmen traditioneller Ansätze wird soziale Wirklichkeit mit Hilfe von Konventionen erklärt, so als gäbe es objektive Regeln, die von Außenstehenden gemacht worden wären und die jeder zu befolgen hätte. Im Gegensatz dazu, und wie SHorrer richtig bemerkt, sind Verhaltensregeln immer Erfindungen, die an andere gerichtete (nicht notwendigerweise mit ihnen "geteilte") Verhaltenserwartungen implizieren; sie können befolgt oder verletzt werden. Wir kommunizieren also immer im Hinblick auf die Möglichkeit, daß unsere sprachlichen Handlungen von anderen geprüft werden könnten. Zwischenmenschliche Kommunikation, das sprachliche Konstruieren anderer, Praktiken gesellschaftlichen Rechenschaftablegens und Verhalten bilden eine kreiskausale Schleife, die koordinierte sprachliche Praktiken, insbesondere die Benutzung von Modellen und Metaphern der Kommunikation, etabliert und damit komplementäre Wirklichkeitskonstruktionen aufrechterhält.

Eine Voraussetzung dieser Studieneinheit war, daß Modelle und Metaphern der Kommunikation eine besondere Rolle in der Konstruktion zwischenmenschlicher Beziehungen spielen:

- Sie werden sprachlich ausgedrïckt, und ihr koordinierender Gebrauch konstituiert (wie oben dargestellt) soziale Wirklichkeiten.

- Sie beziehen sich auf, beschreiben oder organisieren bestimmte Bedingungen sozialen Zusammenlebens, das heißt Kommunikationsbeziehungen, ob diese nun als ein Problem des Transports von Botschaften von einem Ort zum anderen konzipiert werden, als Krieg zwischen Diskutanten oder als Kontrolle des Publikumsverhaltens.

- Sie müssen Kommunikationsprozesse nicht nur realisieren, sondern auch in den von ihnen hervorgebrachten Realitäten kommunizierbar sein, das heißt sich in ihren eigenen Praktiken konstituieren bzw. auf sich selbst anwendbar oder autologisch sein. Modelle und Metaphern der Kommunikation müssen sich in dem Medium, in dem sie praktiziert werden, etablieren können, können dort aber nur bestehen, solange sie zu ihren eigenen Implikaten passen und die Bedingungen ihrer eigenen Gültigkeit erzeugen.

- Die Teilnehmer sehen sich selbst als Teilnehmer an einem von ihnen als Kommunikation konzipierten Prozeß, was auch immer die Modelle oder Metaphern sein mögen, durch die sie sich gegenseitig, aber möglicherweise höchst unterschiedlich, sehen und für welche Aspekte ihres Sprachgebrauchs sie sich auch immer in der Lage sehen, sich gegenseitig Rechenschaft abzufordern und zu geben.

15 John Shotrer: Social Accountability and Selfhood. Oxford 1984. 
Aus konstruktivistischer Sicht sind Modelle und Metaphern der Kommunikation daher in eine doppelte Recursion verwickelt, in der sich die Identitäten ihrer Teilnehmer komplementär, aber sonst relativ unabhängig von anderen Konstruktionen bilden. Das gilt auch für den außenstehenden Beobachter des Kommunikationsverhaltens anderer Personen.

Von den sprachlichen Rollen von Modellen und Metaphern der Kommunikation können wissenschaftliche Kommunikationstheorien nicht ausgeklammert werden. Denn auch Theorien werden sprachlich formuliert, handeln von Kommunikation und müssen sich häufig in genau der Öffentlichkeit bewähren, deren kommunikative Praxis sie zu beschreiben suchen. Die so Angesprochenen können sich diesen Theorien widersetzen, das Gegenteil des theoretisch Vorhergesagten tun, mit ihnen übereinstimmen oder sie als Standard für ihr eigenes Verhalten nehmen. Auch die Begründer von Kommunikationstheorien kann man zur Rechenschaft für das Kommunizieren ihrer Theorien ziehen und sie auffordern, Verantwortung für ihre Konstruktionen zu übernehmen. Auch wissenschaftliche Kommunikationstheorien müssen sich durch die kommunikative Praxis etablieren, die sie in einer Umgebung konstituieren.

Die Erfahrung von Inkohärenzen zwischen der Kommunikationspraxis und den Implikaten entsprechender Theorien, Modelle, Metaphern und anderen Beschreibungen dieser Praxis kann zu Paradoxien, Pathologien oder Zusammenbrüchen sozialer Beziehungen führen. Der Befehl „Widersetze dich meinen Befehlen!" läßt seinen Adressaten entweder in einer lähmenden Unentschlossenheit zwischen seiner Befolgung, womit er sich ihm nicht widersetzt, und seiner Nichtbefolgung, die seiner Befolgung gleichkommt, oder er führt ihn dazu, den Sprecher für inkompetent zu erklären, sich der Situation zu entziehen und damit die Beziehung abzubrechen.

(6) Kommunikationsprozesse setzen eine Dreierbeziehung zwischen Kognitionen, Interaktionen und Institutionen in Bewegung. Kognition ist der ganzheitliche Prozeß, die Wirklichkeiten, die wir sehen, kohärent und aus sich heraus zu konstruieren. Interaktion fügt dem die Konstruktion anderer hinzu, einschließlich Sprache und Technologie, mit deren Hilfe sie sich verständigen. Institution ist die Konstruktion überindividueller Netzwerke von Prozessen, die wir aus Mangel an angemessenem Verständnis zu objektivieren neigen, indem wir ihnen zum Beispiel rechtlichen Status, Persönlichkeit oder übernatürliche Kräfte zuschreiben. Kognitionen, Interaktionen und Institutionen können nicht ohne Kommunikation bestehen, und alle drei sind eingebettet in einen zirkulären, insgesamt rekursiven, sich gegenseitig stabilisierenden und sich selbst abschließenden Prozeß der Konstruktion sozialer Wirklichkeiten.

Kognitionen, Interaktionen und Institutionen implizieren drei Positionen, die Individuen in ihren eigenen Wirklichkeitskonstruktionen einnehmen und zwischen

Abb. 8: Die drei Positionen der Individuen in ihrer Wirklichkeitskonstruktion

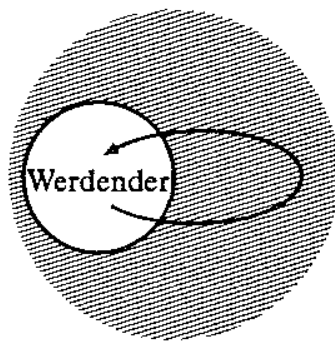

Kognition

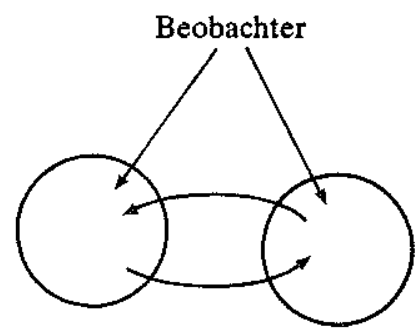

Interaktion

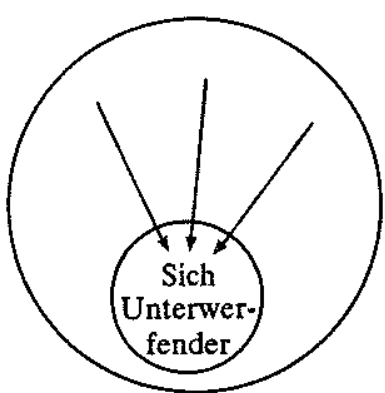

Institution 
denen sie wechseln können. Die mit diesen Positionen verbundenen Rollen möchte ich als Werdender (becoming), Beobachter und sich äußeren Umständen Unterwerfender (subject) bezeichnen.

Werdende sind mit nichts anderem beschäftigt als der Entfaltung ihrer kognitiven Autonomie, der ununterbrochenen Konstruktion, Dekonstruktion und Rekonstruktion ihrer Wirklichkeiten, ihrer eigenen Ökologie des Geistes. Aus diesem Blickwinkel ist Kommunikation weder darauf gerichtet, externe Ziele zu erreichen, noch für von außen herantragbare „Kräfte" verantwortlich zu sein, sondern kann als ein im Selbst stattfindender, kontinuierlich sich selbst erzeugender Prozeß angesehen werden. Kommunikation ist Selbstreflexion. Werdende realisieren sich ständig die Konstruktion ihres Selbst und bewahren ihre Lebensfähigkeit, solange sie sich aktiv mit ihrer Umgebung auseinandersetzen. Sie können sich selbst unwissentlich in die Enge ihrer eigenen Konstruktion treiben, sich in ihr einschließen oder sich aus einer solchen Falle befreien, indem sie Positionen innerhalb ihrer eigenen rekursiven Wirklichkeitskonstruktionen einnehmen, aus denen sie ihr Selbst sehen, de-konstruieren oder re-konstruieren und neu sehen können.

Beobachter hingegen konstruieren und sehen Wirklichkeiten, als wären sie außerhalb des Selbst. Ein Beobachter nimmt konstruktiven Einfluß auf das Beobachtete; er konstruiert es vor seinen Augen. Auch die Position des Beobachters bleibt natürlich stets innerhalb seiner eigenen Wirklichkeitskonstruktion, was ihn deshalb nicht der Verantwortlichkeit für seine Konstruktionen entbindet. Da die Konstruktion des Beobachters selbst im Moment des Konstruierens ungeprüft bleibt, zum Beispiel indem er Kommunikation zwischen Partnern unter Ausschluß seines eigenen Beitrags beschreibt, ist sich der Beobachter seines Einflusses nicht bewußt und weist die Verantwortung für sein Handeln von sich. Beobachterpositionen werden typischerweise von Wissenschaftlern eingenommen, die ihr Untersuchungsobjekt ohne ihre eigene Teilnahme zu beschreiben suchen. Sie sind unvermeidlich für Ingenieure, die neue Technologien erfinden, die allesamt mit Kontroll-Begriffen verbunden werden können.

Sich Unterwerfende sehen sich entweder als determiniertes Teil eines größeren Ganzen, etwa einer sozialen Organisation, oder einer unabhängig von ihnen herrschenden Macht konfrontiert, nach deren Regeln sie sich zu verhalten und deren Struktur sie sich anzupassen suchen. Ohne Zweifel sind diese überindividuellen, ubernatürlichen oder außerhalb menschlicher Erfahrung liegenden Wirklichkeiten von den Sich Unterwerfenden als solche konstruiert, können aber von der darin eingenommenen Position nicht in Frage gestellt oder bezweifelt werden. Sich als Teilnehmer etwa einer sozialen Bewegung erfahren, die konstruierte Natur sozialer Institutionen, wie Konventionen, Kultur oder Staat, zu verleugnen, Göttern überirdische Kräfte zuzuschreiben oder sich von einem erfahrbaren objektiven Universum beherrscht sehen, sind allesamt Beispiele von Wirklichkeiten, deren konstruierte Natur den sich ihnen Unterwerfenden unbewußt bleibt.

Positionen, von denen man seine Wirklichkeiten konstruiert und sieht, können gewechselt werden. Um zum Beispiel in interpersonaler Kommunikation das Gefühl für das Selbst zu bewahren, ist es wichtig, nicht nur die anderen, sondern auch sich selbst durch die Augen anderer sehen zu können, das heißt, aus der Position eines Werdenden in die eines anderen Beobachters des Selbst wechseln zu können (auch wenn all dies innerhalb der eigenen Kognition stattfindet).

Diese drei Positionen führen zu einer Unterscheidung grundlegend unterschiedlicher Ansätze zur Formulierung von Kommunikationstheorien:

- Aus dem Blickwinkel eines Werdenden wird Kommunikationstheorie zur Theorie kommunikativer Kompetenz, das heißt zu einer Theorie, die erklärt, wie Individuen ihre kognitive Autonomie angesichts von Störungen aufrechterhalten 
oder auf Grund welcher Fähigkeiten sie ihre eigenen Wirklichkeitskonstruktionen erfinden, also die kontinuierlichen Prozesse der Dekonstruktion und Rekonstruktion oder die interaktive Entfaltung dieser Konstruktionen er-leben können.

- Aus der Beobachterperspektive wird Kommunikationstheorie zur Theorie der Übertragung von Mustern von einem Medium zu einem anderen bzw. zur Theorie der Medien der Kommunikation, das heißt zu einer allgemeinen Theorie, die erklärt, wie Individuen (einschließlich des Beobachters selbst) ihr Zusammenleben koordinieren, miteinander oder gegeneinander sprechen, wie Handlungsmuster von einem Ort zu einem anderen übertragen und übersetzt werden. Alle Kommunikationstechniken, die auf die Einflußnahme auf andere abzielen, die meisten wissenschaftlichen Kommunikationstheorien, etwa SHANnons mathematische Informationstheorie und die Definition von Kommunikation, die wir $\mathrm{zu}$ Anfang benutzt haben, gehen auf diese Beobachterperspektive zurück.

- In der Position eines sich äußeren Umständen unterwerfenden Subjekts wird Kommunikationstheorie zur Theorie kommunikativer Autorität, das heißt zu einer Theorie, welche die Bedingungen darzulegen sucht, unter denen Individuen ihre kognitive Autonomie abgeben, ihre Wirklichkeitskonstruktionen objektivieren und sich von ihnen dann beeinflussen und beherrschen lassen.

Die Kollegstunde selbst zeigt die Brauchbarkeit des hier vorgestellten Rahmens für das Verständnis von Kommunikationsprozessen als ein sprachliches Praktizieren von Kommunikationsmodellen, -metaphern und -mythen, indem sie ihn auf das Phänomen der Massenmedien anwendet. Die fünf Thesen, die sich daraus ergeben, ermöglichen, das Kommunikationsverhalten der Massenmedien als soziale Institution und die Teilnahme von Individuen aus einer neuen Perspektive zu sehen.

Schließlich vergleiche man unsere gebräuchliche Definition von Kommunikation (als eine Übermittlung von Verhaltensmustern von einem System/Raum/Zeit/ Medium zu einem anderen), wie sie anfangs dieses Beitrags gegeben wurde, mit dem Begriff einer sprachlich ausgedrückten Metapher (als die Fähigkeit, mit einer aus einem Erfahrungsbereich stammenden erklärungskräftigen Struktur einen anderen Erfahrungsbereich neu zu erfahren). Kommunikation, was auch immer das Modell, die Metapher oder der Mythos sein mag, der diese zwischenmenschliche Erfahrung hervorruft, scheint nichts anderes zu sein als eine rekursive Metapher für menschliches Zusammenleben. Die gebräuchliche Definition verwirklicht eben nur eine Klasse möglicher Konstruktionen. Der hier vorgestellte radikal selbst-reflexive Rahmen empfiehlt, verständnisvoll und die Vielfalt alternativer Konstruktionen respektierend mit der Sprache der Kommunikation zu kommunizieren.

Eine solche Theorie befaßt sich unter anderem mit den Fragen, warum Individuen willens sind, Institutionen als ihnen übergeordnet zu konzipieren, warum sie Konventionen als unanfechtbar befolgen, sich gezwungen fühlen, Führern zu folgen, sich von rationalen Argumenten zwingen zu lassen oder das Bedürfnis verspüren, sich einer beobachterunabhängigen (also nicht erfahrbaren) externen Wirklichkeit anzupassen. Im Bereich der Massenkommunikation etwa können Wirkungen von Kommunikation unter Bezugnahme auf den Begriff zugeschriebener Autorität erklärt werden, wie etwa die journalistische Autorität eines Nachrichtensprechers, die künstlerische Autorität eines populären Entertainers, die politische Autorität eines Regierungsbeauftragten, die wissenschaftliche Autorität eines Forschers (der z. B. den Anspruch erhebt, Zugang zu Wahrheiten zu haben, die gewöhnlichen Menschen nicht gewährt werden), die rechtliche Autorität eines Richters usw. Soziale Institutionen, Geschichten und Realitäten sind soziale Konstruktionen, die in jedem Falle von Teilnehmern realisiert werden, 
die in diesen Konstruktionen allerdings verschiedene Positionen einnehmen können, was wiederum zu höchst unterschiedlichem Kommunikationsverhalten führen kann.

Zusammenfassend sei festgestellt, daß der Radikale Konstruktivismus das oben Gesagte nicht nur praktiziert, sondern auch auf die Wissenschaftstheorie anwendet. Er macht dem Forscher bewußt, daß auch er kognitiv verstrickt ist in die Erzeugung seines eigenen Forschungsobjekts, während er es erforscht, und daß er sich einer Teilnahme an institutionellen Praktiken nicht entziehen kann. Dieser Ansatz stellt nicht eine spezielle Theorie der Kommunikation dar, sondern einen wissenschaftlichen Rahmen für das Verständnis der Rolle, welche die verschiedensten Kommunikationstheorien (wie auch die Metaphern der Kommunikation) für die kommunikativen Praktiken spielen. Dieser Rahmen dient zugleich einem kritischen Ansatz, insofern er weniger auf die Beschreibung von Ist-Zuständen zielt als vielmehr auf die Konstruktion dessen, was möglich sein könnte, und von dorther erklärt, warum welche Möglichkeiten nicht realisiert werden. Er ruft Kommunikationsforscher dazu auf, ihre eigene kognitive Autonomie in der Konstruktion von Theorien zu erkennen und im Hinblick auf die Autonomie ihrer Mitmenschen auszuäben, aber soziale Verantwortung für die kommunikativen Praktiken zu übernehmen, welche die Publikation ihrer Kommunikationstheorien darstellt.

Aufgabe 7 Welche Möglichkeiten bietet ein konstruktivistischer Rahmen für Kommunikationsverständnis und Kommunikationspraxis, die eine objektivistisch konzipierte allgemeine Kommunikationstheorie nicht wahrnehmen kann? 


\section{MEDIEN UND}

KOMMUNIKATION KONSTRUKTIONEN VON WIRKLICHKEIT

Das Wissenschaftliche Team:

Klaus Merten

Siegfried J. Schmidt

Siegfried Weischenberg

\section{Studienbrief 3}

Herausgegeben vom Deutschen Institut für Fernstudien an der Universität Tübingen

in Verbindung mit dem Hessischen Rundfunk, dem Norddeutschen Rundfunk, Radio Bremen, dem Saariändischen Rundfunk, dem Süddeutschen Rundfunk, dem Südwestfunk sowie dem Westdeutschen Rundfunk

Redaktion des DIFF: Peter Schmoock (Koordinator) Rolf Geserick

Beate Haussmann Jochen Robes Harri du Bois Goetz-Peter v. Zitzewitz

Redaktion des HR: Jochen Greven (verantwortich) Karl-Heinz Welimann 